\title{
A new view of earthquake and volcano precursors
}

\author{
Keiiti Aki \\ Observatoire Volcanologique du Piton de la Fournaise of the Institut de Physique du Globe, Paris
}

(Received October 14, 2003; Revised February 19, 2004; Accepted April 22, 2004)

\begin{abstract}
A close coupling between monitoring and modeling is needed for a quantitative prediction of volcanic eruption and earthquake occurrence. The need is demonstrated for the volcano, Piton de la Fournaise, for which a relatively simple model can be constructed because of the isolated tectonic setting and can be tested in a short time because of the high rate of eruptions. Our conceptual model (Fig. 2) explains various observations for each of the 49 eruptions since 1972 in terms of the varying conditions of the model elements, allowing inferences on causal relations between consecutive eruptive periods, recognized as alternating active and quiet ones, as well as predictions on the possible eruption scenarios for the future. Lessons learned from the volcano are applied to earthquake prediction in California, and we found a model of earthquake loading process by plate-driving forces that can be effectively constrained by data from the existing seismic network. The model identified that the periods of several years preceding the 1952 Kern County earthquake and the 1989 Loma Prieta earthquake are in the anomalous phase of the loading process. A companion paper by Jin et al. (2004) in the present issue shows that the 1992 Landers earthquake and the 1999 Hector Mine earthquake were also preceded by the period of anomalous loading process.

Key words: Earthquake, volcano, prediction, modeling, monitoring, seismology, loading.
\end{abstract}

\section{Introduction}

The current consensus of the scientific community regarding earthquake prediction was well articulated by Olshansky and Geller (2003) in a conference proceeding titled "Earthquake Science and Seismic Risk Reduction" when they stated "Statistically based forecasts of future seismic activity have a sound scientific basis. On the other hand, deterministic prediction is likely to be an inherently unrealizable goal and there certainly are no immediate prospects." Contrasting the statistical approach with the deterministic one seems to reveal the bottle-neck of earthquake prediction research. I remember that the deterministic wave-theoretical approach in earthquake seismology as described, for example, by Aki and Richards $(1980,2002)$ was unknown in late 1950's. The break-through came with the development of "long-period seismology" by Ewing, Press, Pekeris, Benioff and others, which essentially eliminated complex highfrequency part of the observed signal by the low-pass filtering and explained the remaining part by simple mathematical models of the earth and earthquakes.

In the present paper, I like to suggest the possibility of a similar break-through toward developing deterministic approaches in earthquake prediction. As I shall explain below, I believe that the complex part of precursory signals come from the brittle part of the lithosphere and the starting point toward deterministic approach for earthquake prediction should be eliminating that part from the observed signal. Thus, the first task toward this goal is to separate signals according to their sources. In this respect, the problem of earth-

Copy right (C) The Society of Geomagnetism and Earth, Planetary and Space Sciences (SGEPSS); The Seismological Society of Japan; The Volcanological Society of Japan; The Geodetic Society of Japan; The Japanese Society for Planetary Sciences; TERRAPUB. quake prediction and that of volcano prediction become essentially the same. The ductile part probably involving fluid lies shallower and may be easier to study under a volcano. That is the physical reason why lessons learned from a volcano become useful for earthquake prediction as shown in the present paper.

The traditional method of searching for earthquake precursors was primarily empirical, relying on the data gathered by monitoring networks as exemplified by the evaluation of claims of earthquake precursors by the IASPEI (International Association for Seismology and Physics of Earth's Interior) sub-commission on Earthquake Prediction (Wyss, 1991). Precursory phenomena that sometimes show correlation with the earthquake occurrence, but not consistently in a robust manner, have been discarded as unreliable. I have been in touch with a day-to-day monitoring of an active volcano for 9 years and learned that the traditional way cannot deal with the delicate and complicated interaction between the slowly varying condition of the inferred magma system and the phenomena observed at the surface by a monitoring network. The frame of mind formed in the traditional search for a reliable empirical precursor is too rigid and tends to lead to serious mistakes.

For example, as described later in more detail, I found that predictive relationships established empirically for eruptions during a certain period of the volcanic cycle did not apply to eruptions in another period, simply because the condition of magma system changed. If we apply it blindly to any eruption, it can make a wrong prediction and may be discarded as useless although it is useful for eruptions when the magma system is in the applicable condition. This means a double error, and as described later, I realized that I committed such errors in my past study of earthquake precursors. 


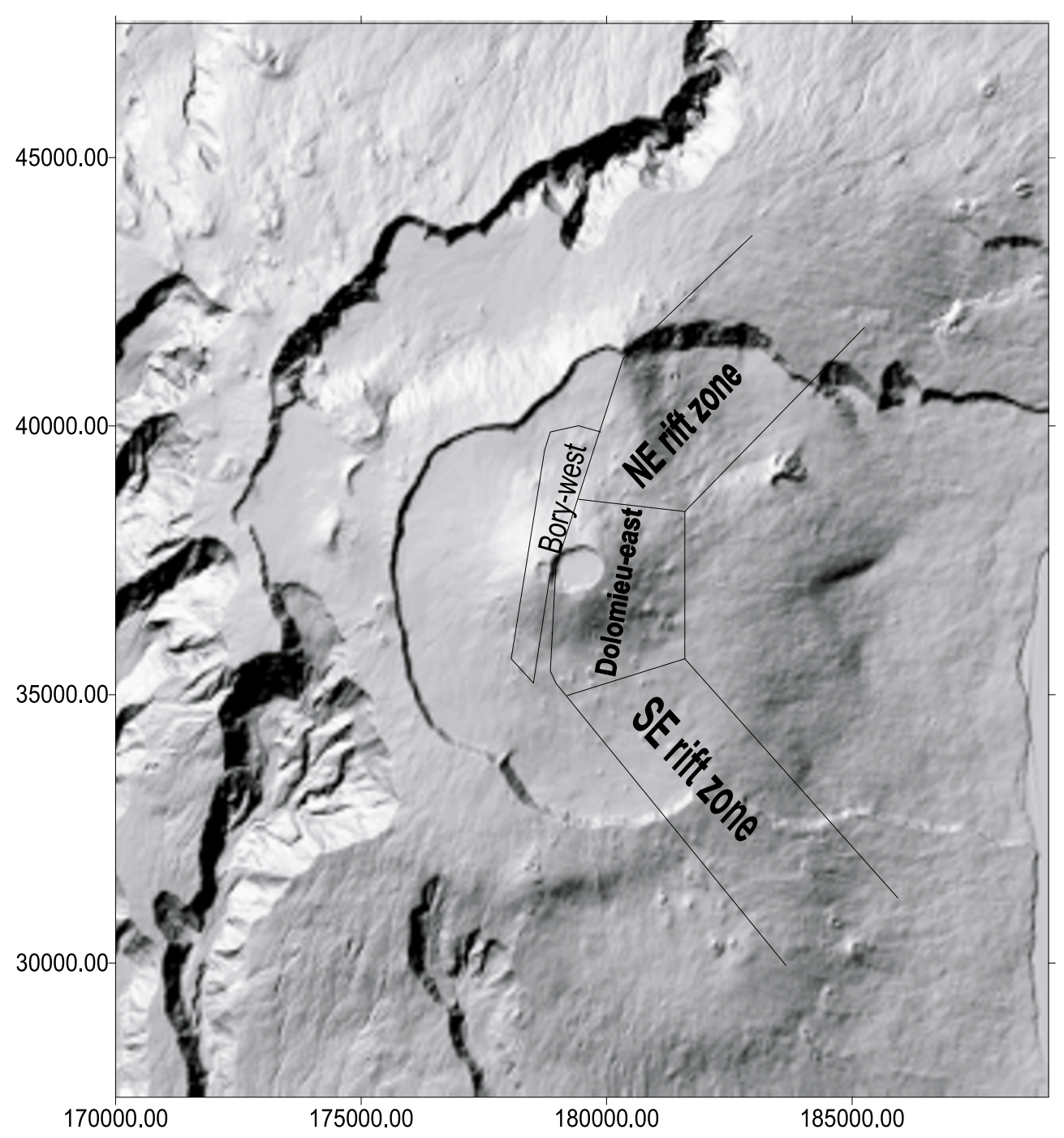

Fig. 1. Four areas of eruption sites at Piton de la Fournaise.

In trying to construct a physical model for interpreting the monitored data at a volcano, I found a need for distinguishing two different types of precursory phenomena. One type is useful for constructing a simple deterministic model for the long-term eruptive cycle, but is not useful for practical prediction of individual eruptions in the traditional sense. The other is of the opposite usefulness, effective for practical prediction of certain aspects of individual eruptions, but not useful for constraining the deterministic model. The latter phenomena appear to be originating from the brittle part of the volcano such as the volcano-tectonic (VT) events, and the former from the part where the fluid magma is involved such as the long-period (LP) events. This difference is physically understandable because the fractal, self-similar nature of the phenomena in the brittle part prevents the construction of a simple deterministic model. On the other hand, the phenomena originating from the part involving fluid magma have unique scale lengths because of the finite structure of the magma system and may show a departure from the selfsimilarity.

Looking at earthquake precursors from this viewpoint, we expect that the phenomena useful for constructing a simple deterministic physical model of the long-term regional cy- cle of earthquake occurrence may not come from the brittle part of the lithosphere, and may be originating from the brittle-ductile transition region, such as silent earthquakes, deep non-volcanic LP events, temporal change in coda $Q$ and various phenomena showing the departure from the selfsimilarity. Some of these phenomena might have been discarded as useless for a practical prediction of the occurrence of individual earthquakes, thereby making the double mistake mentioned above. More specifically, I was drawn back to the observation made by Jin and Aki $(1989,1993)$ about a strong positive and simultaneous correlation between the temporal change in the coda $Q^{-1}$ and the fractional frequency $N(M c)$ of earthquakes with a certain magnitude $M c$ characteristic to a seismic region. The observed correlation was explained by an interaction between the brittle part and the ductile part of lithosphere. This observation is extraordinary because, as far as I know, it is still the only case in which a structural parameter (coda $Q^{-1}$ ) of a seismogenic region showed a strong simultaneous correlation (coefficient higher than 0.8$)$ with a parameter of earthquake process $(N(M c))$ for a long period (about 50 years). Looking back at old observations I recognized that the correlation depended on the long-term regional cycle, and is positive and simultane- 


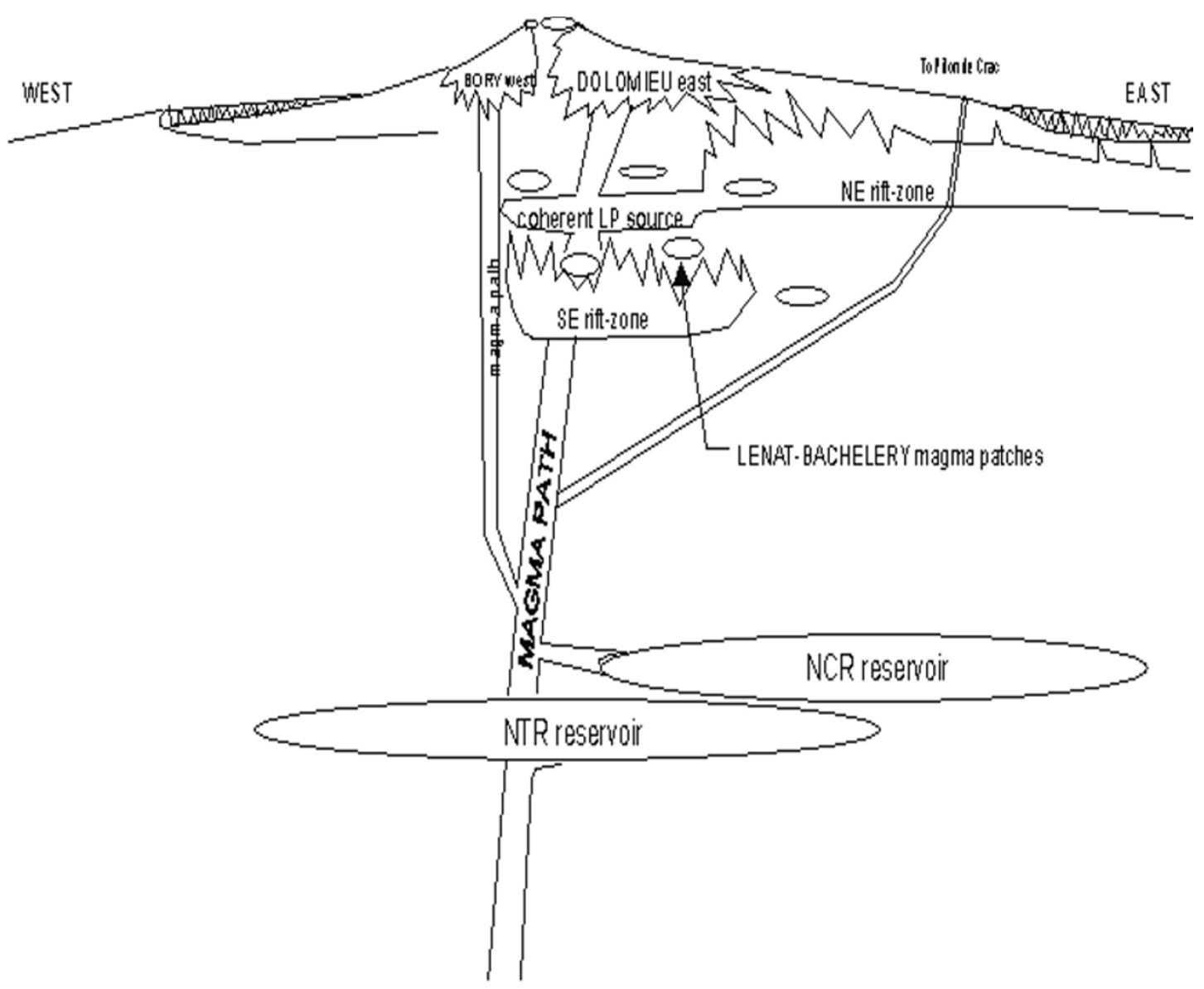

Fig. 2. A model of magma system under Piton de la Fournaise.

ous during the normal period of the loading of the tectonic stress, and the positive simultaneous correlation is disturbed for several years before the largest earthquake of the studied period. As discussed later, this finding is in harmony with the conclusion of Zoback and Zoback (2002) from a global survey of the tectonic stress that the tectonically stable region is stable because of the low rate of deformation in its ductile part, and the active region is active because of the high rate of deformation in its ductile part. It is also consistent with the interpretation of the observed zone of concentrated deformation in Japan by Iio et al. (2002).

In a recent book titled "Nonlinear Dynamics of the Lithosphere and Earthquake Prediction”, Keilis-Borok (2003) put Nonlinear Dynamics and Geodynamics at the opposite ends of the earthquake prediction expanse. From his viewpoint the observed correlation between the coda $Q^{-1}$ and the fractional frequency of earthquakes with magnitude $M c$ mentioned above can be considered as the contact point of the two dynamics, because $Q^{-1}$ is a continuum concept while $M c$ (lower fractal limit of magnitude distribution) is a fractal concept. From this viewpoint, our analogy between the prediction of volcanic eruption and that of earthquake occurrence also comes out naturally, because the VT event is a brittle fractal phenomenon while the source of LP event involves continuum fluid.

\section{Quantitative Prediction of Eruptions at Piton de la Fournaise}

The volcano chosen for the present study is Piton de la Fournaise on the Reunion island in the Indian ocean. It is a basaltic island volcano originating from a hot spot in the mantle like Kilauea, Hawaii. This hot spot has had a long active life and is considered to be responsible for the 65.5 Ma Decan plateau in India. It has been monitored by a permanent network of the Institute of Physics of the Globe of Paris (IPGP) since 1980 offering an ideal experimental site for prediction research because of its high rate of eruption and simplicity of the magma system owing to its isolated tectonic setting.

This volcano has linear eruptive rift-zones like Kilauea as indicated in Fig. 1, but they are not extensive and eruption sites are mostly confined within the caldera called "Enclos" with a diameter of about $10 \mathrm{~km}$. All 49 eruptions since 1972 originated in one of the four areas marked in Fig. 1, namely, Bory-west, Dolomieu-east, NE rift-zone and SE riftzone. Only two of them erupted outside the caldera from fissures extending along the rift-zone. The classification of all eruption sites into the four areas was made unambiguously and uniquely according to the conceptual model depicted in Fig. 2.

The model shown in Fig. 2 was evolved from the one proposed by Aki and Ferrazzini (2000) on the basis of seismic observations made between 1980 and 1998. It was merged harmoniously with the one proposed earlier by Lénat and 


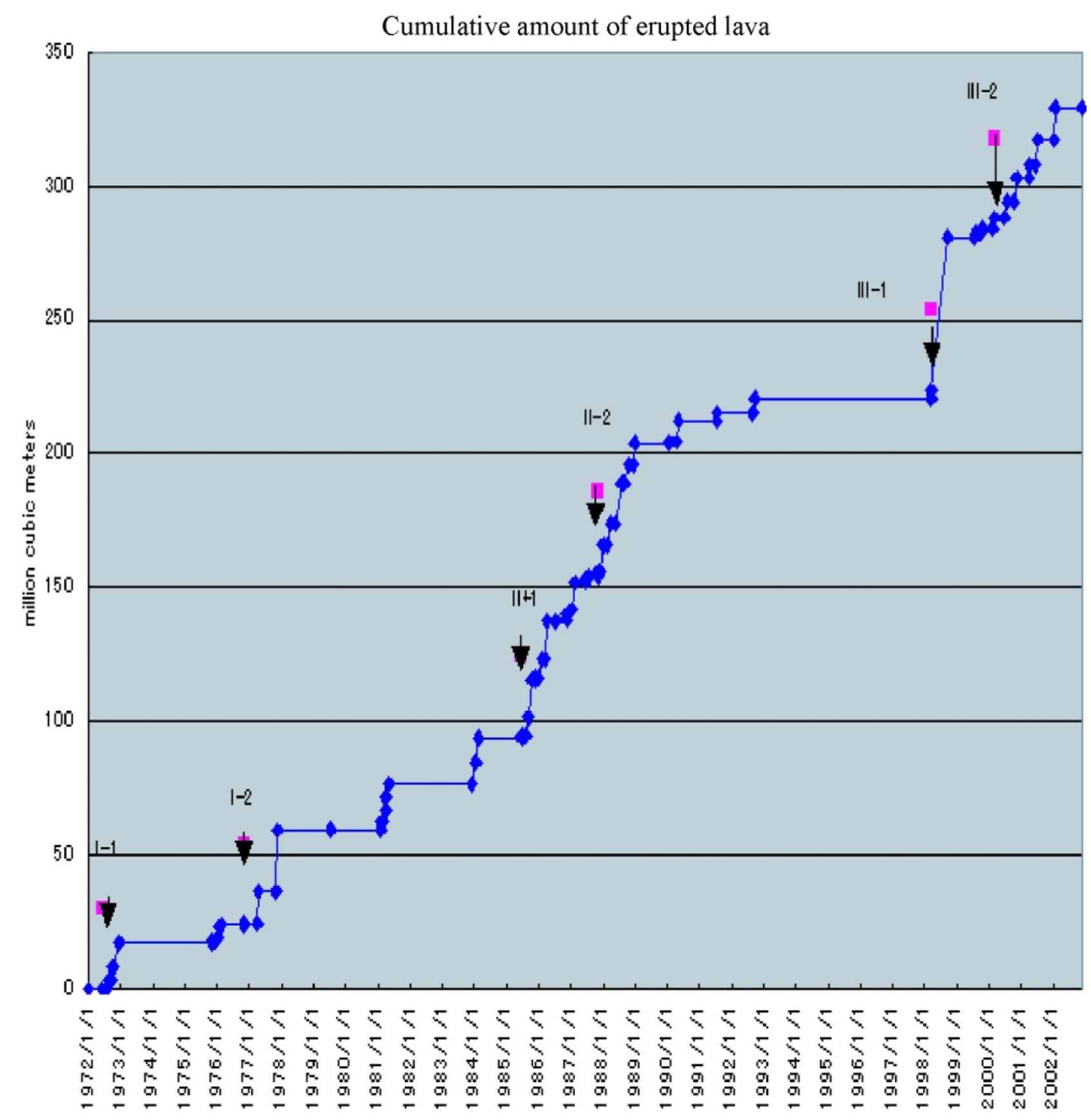

Fig. 3. Cumulative lava output from Piton de la Fournaise in million cubic meters based on the data given in Table A1. The beginning of eruption in the Bory west area identified as the arrival of new magma from the mantle is indicated by an arrow.

Bachelery (1990) based on petrologic, geochemical and geophysical observation, in which patches of magma presumed to have remained from earlier eruptions at shallow part of the volcano supplied the lava output for all eruptions in 1980's. These patches were introduced in our model on the basis of the concurrent temporal change in eruption tremor amplitude with that in the chemical composition of lava during the major eruption of 1998 attributed to mixing of old and new magma by Bachélery (1999). As described in Appendix, the model shown in Fig. 2 explains various observations for each of the 49 eruptions since 1972 in terms of the varying conditions of the model elements, allowing inferences on causal relations between consecutive eruptive periods to be used as the basis for predictions of future eruption scenarios. The dike-like magma path to the Bory-west area was included after the finding that all six active periods, as identified by the sharp rise in the cumulative curve for the erupted lava (shown in Fig. 3 constructed from Table A1), were preceded by an eruption from a narrow zone marked as Bory-west in Fig. 1. The path is connected to the main channel of magma supply at a deep part of the volcanic edifice in our model (Fig. 2). This discovery of the concurrence of a minor eruption in a restricted area preceding an active eruptive period of the volcano was motivated by historic evidence about the concurrent Odawara earthquake to an active period in the earthquake cycle of the Metropolitan Tokyo area as mentioned by Ishibashi (2004) in the present issue. We recognize from Fig. 3 that there were three cycles of eruptive activity since 
Table 1. List of the consecutive eruption periods since 1972 (see text above for explanation of each column) based on the data given in Table A1.

\begin{tabular}{|c|c|c|c|c|c|}
\hline Cycle & Period & Starting date & Duration in month & Erupted lava & Amount in L-B \\
\hline I & $1 \mathrm{~A}$ & $1972 / 6 / 9$ & 12 & 17.4 & 0 \\
\hline I & $1 \mathrm{Q}$ & $1973 / 5 / 29$ & 53 & 12 & 43 \\
\hline I & $2 \mathrm{~A}$ & $1976 / 11 / 2$ & 13 & 35.3 & 31 \\
\hline I & $2 \mathrm{Q}$ & $1977 / 11 / 17$ & 91 & 34.3 & 56 \\
\hline II & $1 \mathrm{~A}$ & $1985 / 6 / 14$ & 10 & 43.7 & 22 \\
\hline II & $1 \mathrm{Q}$ & $1986 / 4 / 5$ & 19 & 16.9 & 38 \\
\hline II & $2 \mathrm{~A}$ & $1987 / 11 / 6$ & 14 & 49.6 & 21 \\
\hline II & $2 \mathrm{Q}$ & $1988 / 12 / 9$ & 110 & 17 & 31 \\
\hline III & $1 \mathrm{~A}$ & $1998 / 3 / 9$ & 6 & 60 & 14 \\
\hline III & $1 \mathrm{Q}$ & $1998 / 9 / 21$ & 17 & 3.3 & 14 \\
\hline III & $2 \mathrm{~A}$ & $2000 / 2 / 14$ & 23 & 45.2 & 11 \\
\hline III & $2 \mathrm{Q}$ & $2002 / 1 / 16$ & & & 26 \\
\hline
\end{tabular}

1972 with the period of 13 years, and each cycle had 2 active phases.

Other elements of the model shown in Fig. 2, such as NTR/NCR reservoirs and LP sources are explained in detail in Aki and Ferrazzini (2000) and their roles in individual eruptions are described in Appendix.

The main magma path inclined to the west is clearly recognizable in 3-D images from seismic tomography obtained by A. Hirn and his coworkers as a high $\mathrm{P}$ velocity body. The presence of a high P-velocity body in the crust under the summit area and rift zone has been well known for the Kilauea volcano in Hawaii since Ellsworth and Koyanagi (1977). It is of high seismic velocity probably because the fluid magma fills cracks and joints of the low-velocity volcanic edifice and solidifies it. The magma conduits must be harder than the surrounding, and we may visualize a system of several such channels connected at a junction below the summit of Piton de la Fournaise. Such a system of channels will cause stress concentration at their junction wherever the fluid flow encounters barriers to overcome. That may be the reason why we observe a swarm of volcano-tectonic events (called summit seismic crisis) originating from practically the same place beneath the summit at about the sea level wherever the fluid moves in the system.

In Fig. 3, we recognized that each of the six active phase started with an eruption in the Bory-west area was followed by a nearly flat curve indicating a quiet period. This let us distinguish 12 alternating active and quiet periods since 1972 as summarized in Table 1 which lists the starting date of each period, its duration in month and the total amount of lava output in million cubic meters for each period. The last column in Table 1 called "amount in L-B" is the amount of magma, at the beginning of each period, left in the Lenat-Bachelery (L-B) magma patches (Lénat and Bachélery, 1990; shown in Fig. 2) from the earlier period assuming that each active period brings 60 million cubic meters from the man- tle into the magma system of the volcanic edifice. To our great surprise, this extremely simple assumption appears to explain well the eruption history since 1972 as described below. We shall attribute this simplicity to the exceptionally simple magma system (as indicated by the maximum magnitude of less than 3.0 for earthquakes associated with Piton de la Fournaise as compared to that of more than 7 under Kilauea suggesting more than 100 times difference in tectonic scale length between the two volcanoes) as well as to the steadiness of magma accumulation in the mantle. The assumption of the steadiness of the deep supply system is supported by the stationary occurrence of deep tremors observed by Aki and Koyanagi (1981) even under Kilauea. In calculating the last column, it is also assumed that there was no left-over magma in the system before the period I-1A, which may be justified by the long quiescence preceding the period as well as the large eruptions in 1961 and 1964-66 which might have emptied the shallow magma system. If it is not zero, we can correct the column by simply adding the number chosen for the period I-1A to each number listed in the column.

Appendix will give the details of various observations made visually as well as by the monitoring network for each period and interpret them in terms of the changing condition of the magma system model shown in Fig. 2. We found that although the deep supply system from the mantle showed the 13-year periodicity, the phenomena at the more brittle shallower part did not show this regularity. This recognition of depth-dependent difference in observed phenomena led me to suggest the need for eliminating precursory signals originating from the brittle part for a deterministic modeling as mentioned in the beginning of this paper. We searched for any causal relationships between the mode of eruption and the condition of the magma system for all consecutive periods as described in Appendix and tried to use them as the basis for a quantitative prediction of eruptions in the future. 
The prediction for the next decade as of April, 2003 is summarized below.

The volcano is currently in the quiet period of phase 2 of cycle III, designated as III-2Q. We had already one eruption (December, 2002) in the current period. Table 1 shows the current estimate of remaining magma in the L-B patches to be $26 \mathrm{M}$ cubic meters minus whatever erupted in the December, 2002 eruption, which is significantly smaller than the amount (31 M cubic meters) estimated for the beginning of the corresponding period of the last cycle, namely, II-2Q. With the increase of pressure in these patches we may have minor eruptions in the next several years, but the total amount of lava output during the current period, III-2Q, would be smaller than that of II-2Q (17 M cubic meters).

If the system of magma supply from the mantle stays in the same condition as in the past 30 years, we expect the next arrival of new magma in 2011, 13 years after 1998. We notice in Fig. 3 the decreasing trend in the time interval between the beginning of phase 1 and that of phase 2 during the 30-year period, and the best fitting model of Cabusson (2002) using the computer program developed by Aki and Ferrazzini (2001) predicts a simultaneous arrival from the two mantle reservoirs for the next active period. This means that there will be $120 \mathrm{M}$ cubic meters of magma to be supplied to the shallow magma system in 2011. If the flow rate between the mantle reservoir and the NTR/NCR reservoirs (shown in Fig. 2) in the edifice is the same as in 1996-98 as described in Aki and Ferrazzini (2000), the filling will take 15 months. The arrival of new magma of $120 \mathrm{M} \mathrm{cu}-$ bic meters in 15 months at depths around $5 \mathrm{~km}$ b.s.l. should be detectable by the satellite geodesy. As discussed in Aki and Ferrazzini (2001), the absence of precursory signal from the satellite geodesy for the 1998 eruption (Sigmundsson $e t$ al., 1999) is marginally compatible with the accumulation of magma of $60 \mathrm{M}$ cubic meters at this depth. The monitoring network will record an increase in regional seismicity with focal depths in the range 10 to $30 \mathrm{~km}$ for several years before the arrival of new magma as in 1993-98 (see figure 10 of Aki and Ferrazzini, 2000) as well as the upward migration of VT events beneath the summit area as before the March, 1998 eruption.

The shallow magma system at the time of arrival of new magma from the mantle will be the least developed of all periods for which the monitored data exist, and may be comparable to the condition preceding the period I-1A. I predict that the first eruption will be from the Bory-west area as usual, and may be followed by eruptions in the peripheral areas of the Dolomieu-east and the two rift-zones such as in the period I-1A. We cannot exclude the possibility of an eruption in the NW rift-zone as occurred in 1820. Because of the underdeveloped condition of the shallow magma system, there would be no eruption in the rift-zone outside the Enclos caldera (which may affect resident populations) nor the pit-crater collapse in the Dolomieu crater (which may affect tourists).

The above scenario would imply a relatively small amount of erupted magma during the next active period as in the period I-1A, leaving a large amount of magma in many LB patches. Another possible scenario is the repeat of the 1998 eruption, in which a large amount of lava flow comes out in a single eruption in the NE rift zone. In either case, the eruption will be primarily confined within the Enclos caldera where nobody lives.

The monitoring network can tell us, at an early stage of the next active period, which scenario will be followed. A cookbook type description for possible scenarios corresponding to the observed behaviors of seismic events may be constructed by distilling the content of Appendix, but it is beyond the scope of this paper.

We like to emphasize that the above prediction was not possible solely from the empirical curve of the lava output shown in Fig. 3. We also need constant monitoring observations as well as modeling. Our prediction may be wrong if some unexpected change occurs in the magma system, but the monitored data can tell us about the change and we shall be able to quickly adjust our model. The prediction based entirely on the past data does not have this flexibility. Thus a close coupling between monitoring and modeling is essential not only for understanding the precursory phenomena but also for prediction practice.

Now let us turn to the earthquake precursor. We shall start with a model of the loading process of plate-driving forces widely believed to be the cause of earthquakes.

\section{Earthquake Loading by Plate-Driving Forces}

After a thorough survey of the tectonic stress in the Earth's lithosphere based on observations about its brittle part, Zoback and Zoback (2002) offered a new perspective on the role of its ductile part in the earthquake loading process by plate-driving forces. Assuming that a three-layer lithosphere composed of the brittle upper crust and the ductile lower crust and upper mantle, as a whole, support platedriving forces (Zoback and Townend, 2001), they concluded that the tectonically stable region is stable because of the low rate of deformation in its ductile part, and the active region is active because of the high rate of deformation in its ductile part. They state that because of the applied force to the lithosphere will result in steady-state creep in the lower crust and upper mantle, as long as the three-layer lithosphere is coupled, stress will build up in the upper brittle layer due to the creep deformation in the layer below. The lithosphere model proposed by Iio et al. (2002) for explaining various observations related to a zone of concentrated deformation in the inland Japan may be considered as a regional scale version of this brittle-ductile interaction model.

Above models imply a simultaneous occurrence of the higher (lower) rate of stress increase in the brittle part and the higher (lower) rate of deformation in the ductile part due to plate-driving forces. This is exactly how Jin and Aki (1989, 1993) interpreted the strong positive simultaneous correlation between coda $Q^{-1}$ and the fractional frequency $N(M c)$ of earthquakes with a certain magnitude $M c$ (characteristic to a seismic region) observed both for Central California and Southern California. $N(M c)$ is simply the frequency of earthquakes within a magnitude window around $M c$ divided by the frequency for the total magnitude range under study. For those who have never heard of coda $Q^{-1}$, a brief definition of seismic coda waves and coda $Q^{-1}$ may be needed here.

When an earthquake or an underground explosion occurs 

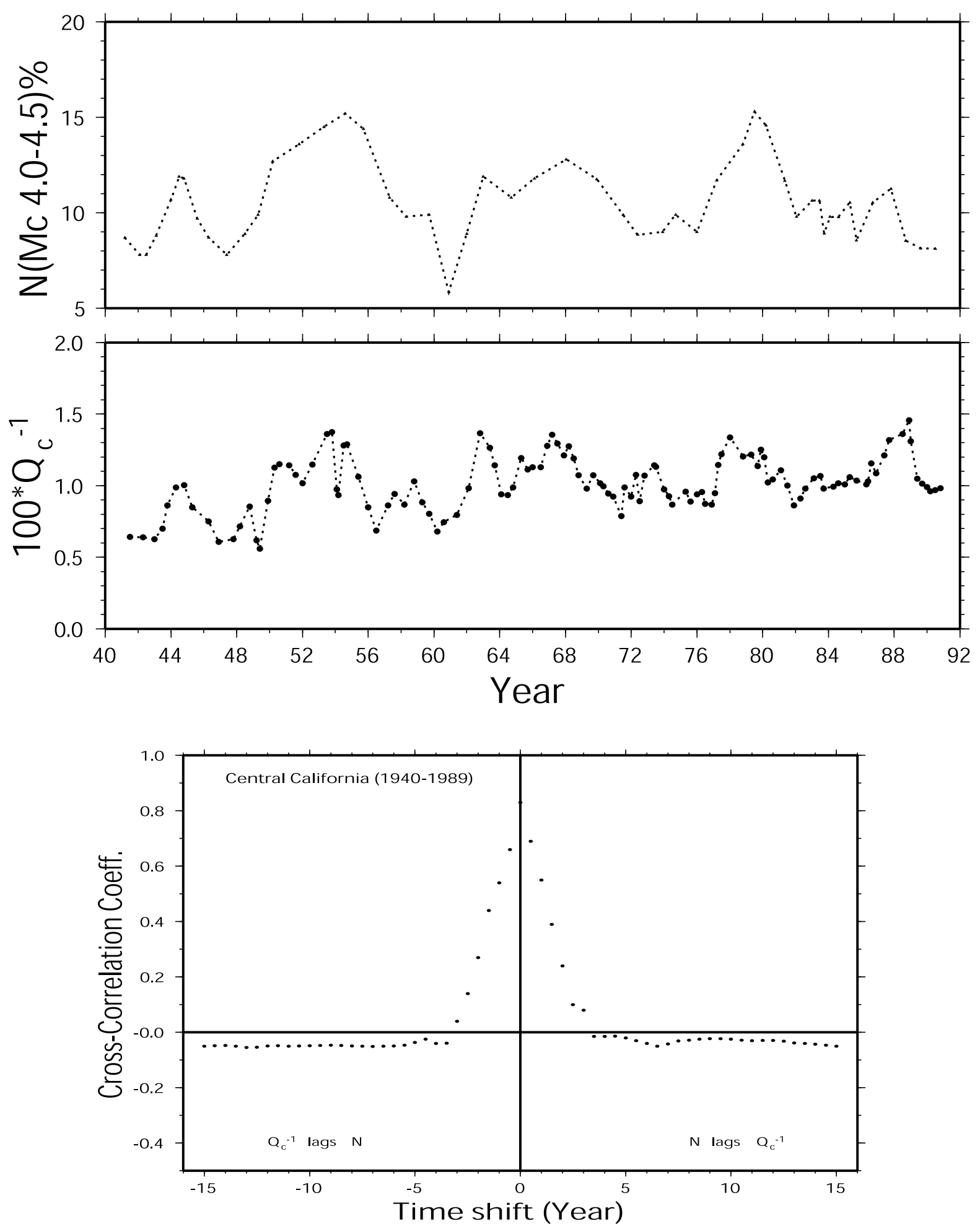

Fig. 4. Comparison of coda $Q^{-1}$ and the relative frequency $N(M c)$ of earthquakes with $M c$ between 4 and 4.5 observed for Central California for the 50-year period since 1941. The cross-correlation function between them is also shown (reproduced from Jin and Aki, 1993).

in the earth, seismic waves are propagated away from the source. After $\mathrm{P}$ waves, $\mathrm{S}$ waves and various surface waves are gone, the area around the seismic source is still vibrating. The amplitude of vibration is nearly uniform in space, except for the local site effect, which tends to amplify the motion at soft soil sites as compared to hard rock sites. This residual vibration is called seismic coda waves, and decays very slowly with time. The rate of decay is measured by coda $Q^{-1}$, which is independent of the locations of seismic source and recording station, as long as they are in a given region (Sato and Fehler, 1998).

The closest phenomenon to the coda wave is the residual sound in a room, first studied by Sabine (1922). If one shoots a gun in a room, the sound energy remains for a long time due to incoherent multiple reflections. This residual sound has a very stable, robust nature similar to seismic coda waves, 

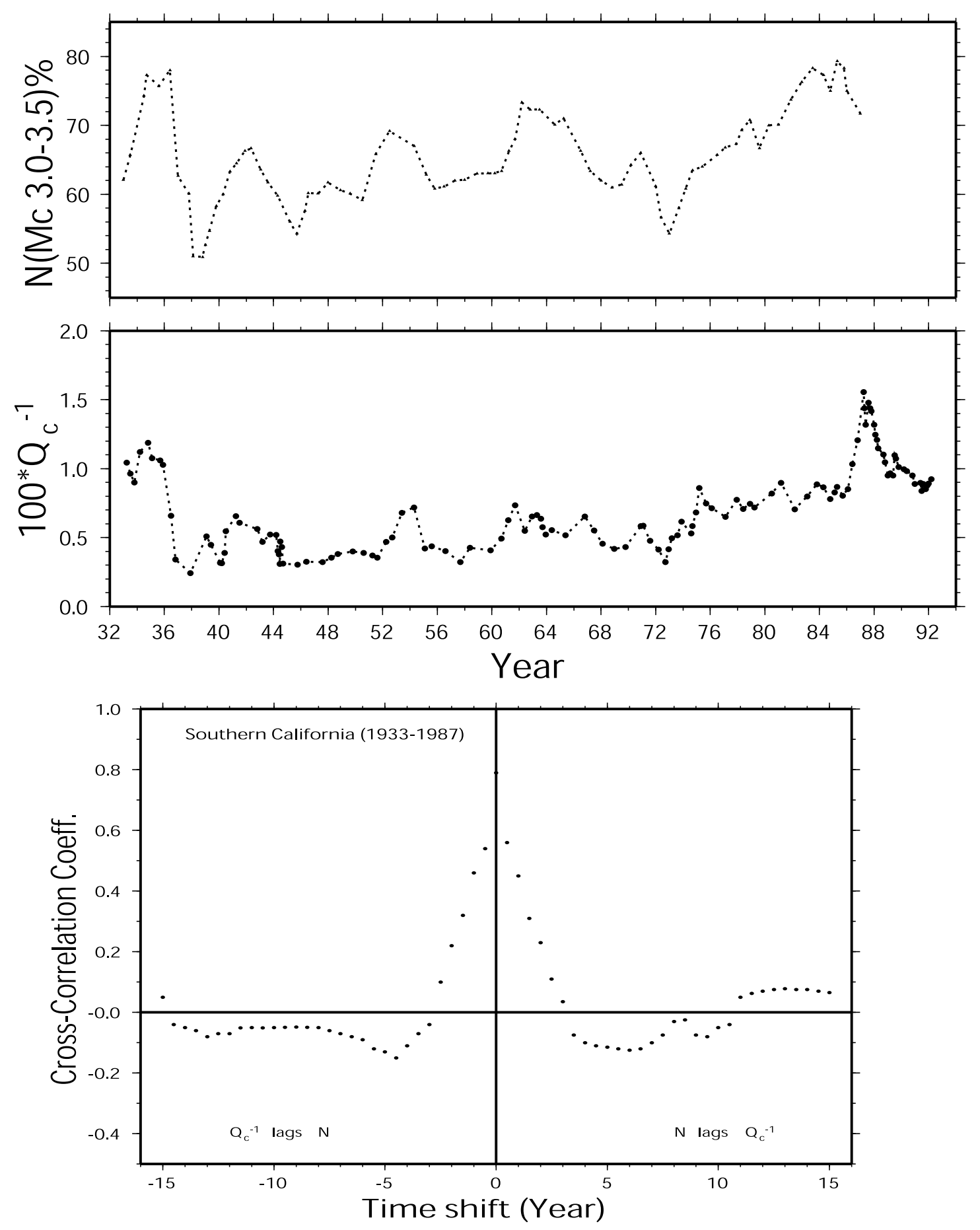

Fig. 5. Comparison of coda $Q^{-1}$ and the relative frequency $N(M c)$ of earthquakes with $M c$ between 3 and 3.5 observed for Southern California for the 60-year period since 1933. The cross-correlation function between them is also shown (reproduced from Jin and Aki, 1993).

independent of the locations where you shoot the gun or where you record the sound in the room. The residual sound remains in the room because of multiple reflections at rigid wall, ceiling and floor of the room and its decay rate reflects the over-all absorptive property of the room. Since we cannot hypothesize any room-like structure in the earth, seismic coda waves are attributed to back-scattering from numerous heterogeneities in the earth since Aki (1969). The coda $Q^{-1}$ has been shown to lie between the intrinsic $Q^{-1}$ of $\mathrm{S}$ waves and their total $Q^{-1}$ including the scattering attenuation for several regions of the earth by Jin et al. (1994).
Figure 4 shows the 50-year records of the two time series for Central California with the cross-correlation function, and Figure 5 shows the same set of curves for nearly 60 years for Southern California reproduced from their papers. Both are reproduced from Jin and Aki (1993) (See Jin et al. (2004) in the present special issue for the precise area sampled for each figure.). It is clear that the correlation between coda $Q^{-1}$ and $N(M c)$ is simultaneous and positive with the correlation coefficient higher than 0.8 for both regions. As mentioned in the introduction, as far as I know, these observations offer the only case in which a structural parameter of 
a seismogenic region (coda $Q^{-1}$ ) showed such a strong correlation with a parameter of earthquake process $(N(M c))$ for such a long time. Jin and Aki (1993) explained the observed correlation assuming the presence of ductile fractures in the brittle-ductile transition zone with a unique scale length characteristic to a seismic region. The increase in fractures in the ductile part increases coda $Q^{-1}$ and, at the same time, generates stress concentration with the same scale length responsible for the increase in relative frequency of earthquakes around magnitude $M c$. The scale length corresponding to the observed $M c$ is a few hundred meters for Southern California and roughly $1 \mathrm{~km}$ for Central California. This slight difference may imply some tectonic scale difference between the two regions, but the discussion on the possible cause of the difference is beyond the scope of this paper.

When the stress in the brittle part builds up over time to the point of failure preparing for a major earthquake, we may expect a change in its mechanical property as a whole as suggested in various laboratory experiments on rock samples. There is, however, an important difference between laboratory and nature. In the controlled experiment in laboratory, the loading is a fixed condition given externally by the experimental device. In nature, the loading is an internal process that is likely influenced by the change in the property of the material being loaded. We then expect a change in the mode of loading as the brittle part undergoes such a change preparing for a failure. We may expect the break down of the positive simultaneous correlation between coda $Q^{-1}$ and $N(M c)$. That was exactly what we found for several years before the M6.9 Loma Prieta earthquake of 1989 and also for several years before the M7.3 Kern County earthquake of 1952 as can be seen by the comparison of original time series shown at the upper part of Figs. 6 and 7. The lower parts of Figs. 6 and 7 show the cross-correlation function between the two time series for the Loma Prieta and Kern County earthquake, respectively, in the same format as Figs. 4 and 5 . Figure They show clearly that the correlation between the two time series is no longer simultaneous, but the coda $Q^{-1}$ change attributed to the ductile part is delayed by about 1 year relative to that of $N(M c)$ attributed to the brittle part before both earthquakes. This sense of delay is consistent with the idea that the simultaneous correlation is disturbed by the change in the property of the brittle part of lithosphere as mentioned above. The companion paper by Jin et al. (2004) confirms a similar sense of time shift between the two time series for the period several years before the M7.3 Landers earthquake of 1992 which is just at the data limit of Jin and Aki (1989). Except for these three periods, the positive simultaneous correlation appears to hold always well for both regions, enabling us to make prediction for both safety and danger from a major earthquake with a time scale of a few years.

\section{Comparison with the Loading by Fault Slip in an Earthquake}

Recently much attention has been given to the triggering of earthquakes by the stress induced by the fault slip of a major earthquake in spite of its secondary nature in the loading process of plate-driving forces. It was found that, in the work of Hiramatsu et al. (2000), their effects on coda
$Q^{-1}$ and seismicity are different from what we saw as the manifestation of the loading by plate-driving forces.

The Tamba, Japan, region is adjacent to the epicentral area of the Hyogo-ken Nanbu (Kobe) earthquake of 1995 and is well covered by a high quality seismic network. The seismicity of the Tamba region and its surrounding area in Japan has been studied with special attention to the depth of the brittle-ductile transition zone inferred from the maximum focal depth by Ito (1990). More than 8000 earthquakes in the magnitude range from 1.8 to 5.3 were relocated and it was found that the frequency of occurrence of hypocenters per unit focal depth increases with depth down to about 10 $\mathrm{km}$ and sharply drops beyond about $12 \mathrm{~km}$. There is a remarkable similarity between the observed depth distribution of hypocenters and the theoretical distribution of the shear resistance based on Byerlee's law (Byerlee, 1978; Sibson, 1982) for the brittle part and the dislocation creep law for the ductile part. Ito (1990) made a contour map of the depth of brittle-ductile transition in this region, and found a similarity with the map of the Curie point derived from aeromagnetic surveys by Okubo et al. (1989). The comparison with the Curie point depth as well as the heat flow data gave an estimate of the temperature at which the brittle-ductile transition occurs. In the Tamba region, the brittle ductile transition occurs at depths around $14-16 \mathrm{~km}$ corresponding to a temperature around $300^{\circ}-350^{\circ} \mathrm{C}$.

The Hyogo-ken Nanbu earthquake (M7.2), on January 17, 1995 produced a significant change in the tectonic stress in the Tamba region. The sudden increase in the seismicty in the Tamba region after the earthquake was attributed to the increase in the Coulomb failure function by about 0.04 MPa (Hashimoto et al., 1996). The average increase in shear stress at a depth of $10 \mathrm{~km}$, close to the depth of brittle-ductile transition zone, on the vertical plane trending over the study area was estimated to be about $0.02 \mathrm{MPa}$ by Hiramatsu et al. (2000).

The seismicity of the Tamba region increased significantly after the Hyogo-ken Nanbu earthquake with the hypocenter distribution and focal mechanism indistinguishable from those before the earthquake according to Katao et al. (1997). However, a significant change in coda $Q^{-1}$ was observed for the two frequency bands centered at 3 and $4 \mathrm{~Hz}$. Coda $Q^{-1}$ may change due to the change in the epicenter locations, focal depth distributions, and focal mechanisms of the earthquakes used for the analyses, and their effects were carefully examined and all rejected by Hiramatsu et al. (2000). The change in coda $Q^{-1}$ is about $20 \%$, and its statistical significance is confirmed by the Student's t test with a confidence level of $99 \%$. The above change in coda $Q^{-1}$ combined with the estimated change in tectonic stress mentioned earlier gives the stress-sensitivity of about $10 \%$ change per 0.01 $\mathrm{MPa}(0.1 \mathrm{bar})$. Applying this sensitivity to the observed coda $Q^{-1}$ for Central and Southern California shown in Figs. 4 and 5, we find that the fluctuation of coda $Q^{-1}$ over the 50year period corresponds to the change in stress of the order of $0.1 \mathrm{MPa}$ (1 bar).

The frequency dependence of the change in coda $Q^{-1}$ found in the Tamba region by Hiramatsu et al. (2000) may be attributed to scattering attenuation by fractures. According to Yomogida and Benites (1995), the scattering of seismic 

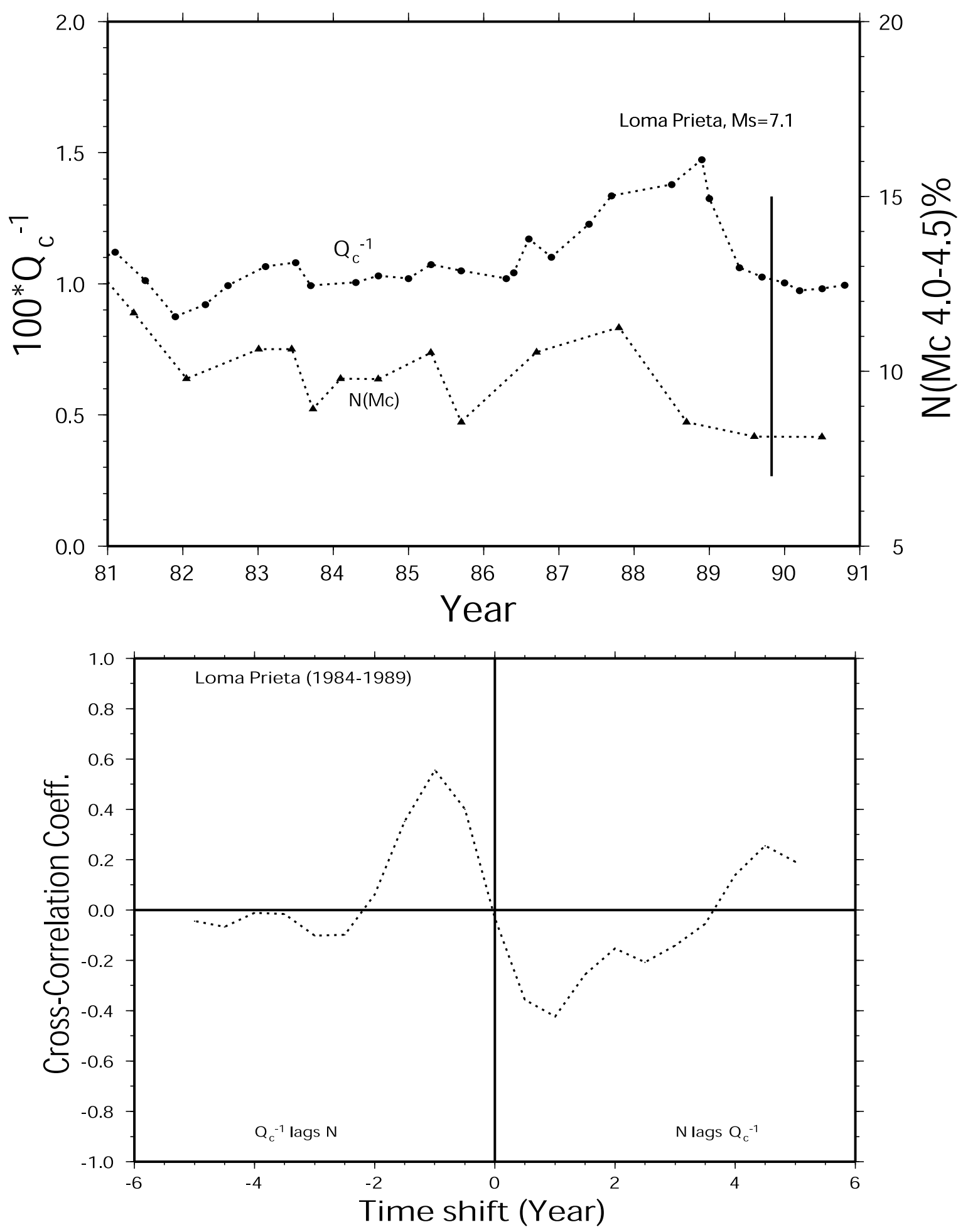

Fig. 6. A closer look at the relation between coda $Q^{-1}$ and $N(M c)$ for several years before the Loma Prieta earthquake of 1989 . The cross-correlation function between them is shown for the 5-year period preceding the Loma Prieta earthquake. The simultaneous correlation shown in Fig. 4 is destroyed by a 1 -year delay of the coda $Q^{-1}$ relative to $N(M c)$.

waves by a fracture is most effective when the wave length is comparable to twice the characteristic length of the fracture. The seismic wave length for which the change in coda $Q^{-1}$ was significant (frequency bands centered at 3 and $4 \mathrm{~Hz}$ ) is around $1 \mathrm{~km}$ corresponding to the characteristic size of the fracture of $500 \mathrm{~m}$, which agrees well with the creep fracture size proposed to explain the correlation between coda $Q^{-1}$ and $N(M c)$ for California.
Hiramatsu et al. (2000) suggested that the observed change in $b$-value might be consistent with the creep model of Jin and Aki $(1989,1993)$. A closer look at the observed change in the frequency of earthquakes in different magnitude ranges, however, reveal that there was no selectively higher increase in the magnitude range around $M c$ (a little over 3 for this case) corresponding to the size of $500 \mathrm{~m}$. In fact, numerous recent studies on the triggering of seismic- 

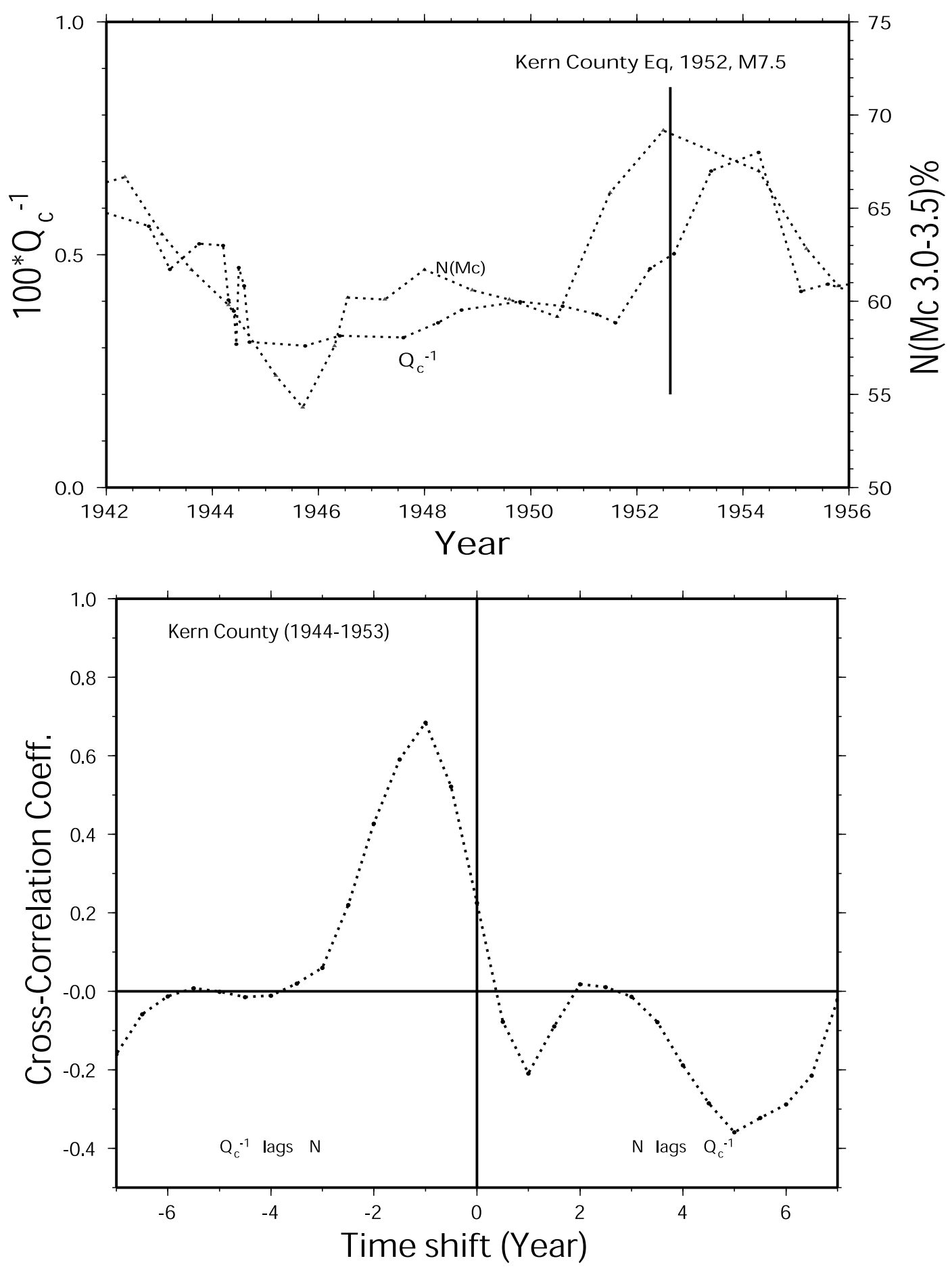

Fig. 7. A closer look at the relation between coda $Q^{-1}$ and $N(M c)$ for several years before the Kern County earthquake of 1952 . The cross-correlation function between them is shown for the 8-year period including the Kern County earthquake. The simultaneous correlation shown in Fig. 5 is destroyed by a 1-year delay of the coda $Q^{-1}$ relative to $N(M c)$.

ity by fault slip during some major earthquakes appear to show a uniform increase of the seismicity independent of magnitude. Such a uniform increase may be attributed to the mode of loading that is originated locally in the brittle part without the active participation of the ductile part envisioned earlier in the brittle-ductile interaction model of platedriving forces. The fractures in the ductile part responded only passively with negligible additional contribution to the seismicity increase. The above recognition of the difference between plate-driving forces and the local source of stress in the brittle part is fundamentally important in understanding the earthquake loading processes.

\section{The Brittle-Ductile Transition: Origin of $\boldsymbol{M c}$}

The scale-invariance in earthquake phenomena, sometimes called the self-similarity, has been widely manifested in various seismological observations such as the magnitudefrequency relation, the aftershock decay rate, and the scaling law of seismic spectrum. The scale-invariance means that the only length scale governing earthquake phenomena is the 
earthquake source size, implying that a seismogenic region has no structure. Although there have been some evidence in support of a departure from the self-similarity at large scales (e.g., Shimazaki et al., 1986) as well as at small scales (e.g., Aki, 1996), it is true that the earthquake phenomena as a whole are dominated by the self-similarity.

On the other hand, there is a class of seismic events originating from volcanoes which show spectral features indicating the presence of some structure in the source region. They are long-period (LP) events and volcanic tremors associated with the pressure fluctuation in fluid magma and/or gas contained in the solid earth (see Chouet, 2003, for the latest review on Volcano Seismology). They have characteristic band-limited spectra independent of amplitude, clearly indicating the existence of structure in the source region, namely, structure of the magma system. Recent discovery of deep non-volcanic LP events distributed in a long narrow zone between the Eurasian plate and the down-going Philippine Sea plate in Southwest Japan by Obara (2002), however, suggests the pervasive existence of such a structure throughout the ductile region between the two plates. Their observed frequency band of 2 to $5 \mathrm{~Hz}$ is similar to those observed beneath volcanoes in Japan and elsewhere in the world. The fact that coda $Q^{-1}$ showed a significant change in the Tamba region by the occurrence of the Hyogoken Nanbu earthquake at a similar frequency range $(3-4 \mathrm{~Hz})$ suggests a common origin for the ductile fracture hypothesized in the brittle-ductile transition zone and the source of deep non-volcanic LP events. It is natural to imagine that the ductile fractures responsible for the temporal change in coda $Q^{-1}$ might generate LP events when sufficient fluid is injected to them from the subducting plate.

The above reasoning suggests further that the departure from the self-similarity may be found for earthquakes occurring in or near the brittle-ductile transition zone influenced by the unique structure on the ductile part. In fact, some of the clearest cases of such a departure includes the Matsushiro, Japan, earthquake swarm (Sacks and Rydelek, 1995) believed to involve water in the source volume and the Mammoth Lakes, California, earthquake sequence studied by Archuleta et al. (1982) close to a volcanic area. In both cases, the corner frequency tended to remain at a constant value with decreasing magnitude below about 3 implying the influence of some structure with the scale length of a few hundred meters. This characteristic scale length may be varying locally, because we found the value of $M c$ to be 4 to 4.5 in optimizing the correlation between coda $Q^{-1}$ and $N(M c)$ for the area selected in our study for Central California which marginally includes the Mammoth Lakes area.

A direct support for the existence of a structure with the scale length of a few hundred meters in the brittle-ductile transition zone comes from a study of the Hatagawa fault in Northeast Japan, which is believed to be an exhumed brittle-ductile transition zone. Ohtani et al. (2001) described a cataclasite zone with the width of about $100 \mathrm{~m}$ formed under temperature range $200^{\circ}$ to $300^{\circ} \mathrm{C}$ and the appearance of mylonite with the maximum width of $1 \mathrm{~km}$ in the fault zone and discussed evidence for the coexistence of plastic deformation and brittle rupture in the zone.

Further support comes from a numerical simulation of de- formation in the brittle-ductile transition zone by Shibazaki (2002), who found an appearance of cell-like structure with enhanced slip rate near the transition zone. He uses a fault model specified by the slip-weakening constitutive law of Ohnaka et al. (1997) with appropriate parameters chosen for various depths covering the brittle part, transition part and ductile part. The primary purpose of the simulation was to study the nucleation of earthquake rupture in the brittle part, but it may be extended to study the steady-state loading process of plate-driving forces for the three-dimensional, threelayer model of Zoback and Townend (2001) using constitutive relations applicable to each layer.

\section{Discussions}

In this paper we presented a hypothesis about the loading process of tectonic stress by plate-driving forces in preparing for major earthquakes, which may be called "BrittleDuctile Interaction Hypothesis". Although we discussed only the cases of the 1952 Kern County earthquake and the 1989 Loma Prieta earthquake in support of our hypothesis, our hypothesis is applicable to the following four additional cases as summarized in the companion paper by Jin et al. (2004); (1) the 1983 Misasa earthquake $(M=6.2)$ studied by Tsukuda (1988), (2) the 1995 Hyogoken-Nanbu (Kobe) earthquake ( $M=7.2$ ) studied by Hiramatsu et al. (2000), (3) the 1999 Hector Mine earthquake $(M=7.1)$ and (4) the normal loading period at Stone Canyon, California studied by Chouet (1979).

Central to the assertion of our hypothesis is the temporal correlation between coda $Q^{-1}$ and $N(M c)$ observed by Jin and Aki $(1989,1993)$ and generally disregarded by the seismological community although Aki $(1995,1996)$ brought it up repeatedly. The general disregard is understandable because it involves two of currently most controversial issues in Earthquake Seismology, namely, the departure from the selfsimilarity (or the existence of $M c$ ) and the temporal change in coda $Q^{-1}$. With regard to $M c$, the controversy may be resolved if we can attribute its existence to the influence of ductile fracture in the manner explained in the preceding section. The controversy regarding the coda $Q^{-1}$, however, is partially rooted in traditional skeptical views of seismologists on the stochastic modeling approach to the structural study of the earth. The skepticism seems to persist in spite of numerous works in the past several decades along this line as summarized in a book by Sato and Fehler (1998).

The images of the earth obtained from the stochastic modeling may not be definitive, but I believe it can demonstrate the existence of small-scale heterogeneities in the earth that may be smoothed out in the widely accepted deterministic approach. From my own personal experience, for example, the recognition of the 3-D heterogeneity of the lithosphere with the length scale of $10 \mathrm{~km}$ under a large aperture seismic array in Montana, U.S. using a random media modeling based on the Chernov theory (Aki, 1973) gave the image of a clear target for the deterministic inversion procedure (Aki et al., 1977) first applied to another such array in Norway and later developed as Seismic Tomography. The estimated parameters of the random media convinced me that the deterministic inversion of the travel time data collected at a 2-D seismic array would produce a geologically significant 3-D 
image of the lithosphere. Thus, a stochastic modeling prepared the path leading to a deterministic modeling. I hope that our finding that the ductile fractures with the scale length of a few hundred meters in the brittle-ductile transition zone may be playing a key role in the earthquake loading process would give another productive target for seismologists.

Acknowledgments. I benefited greatly from an anonymous review in revising the manuscript extensively. This paper was not possible without the Observatory of Piton de la Fournaise operated since 1980 by the Institute of Physics of the Globe of Paris (IPGP) and I am grateful for its generosity in giving me a free, easy and complete access to the high quality data gathered and accumulated there. The work presented here has been supported in part by the Association for Development of Earthquake Prediction (ADEP) in Japan and I gratefully acknowledge Dr. Akio Takagi of ADEP for his encouragement. Special thanks are due to Dr. Anshu Jin of NIED/ADEP for providing the cross-correlation functions in Figs. 6 and 7 as well as for her total help in preparing the manuscript.

\section{Appendix. The Eruption History of the Piton de la Fournaise since 1972}

In the following, I shall first describe briefly various observations for each period. Then I shall interpret them in terms of our model of the magma system shown in Fig. 2. Finally possible causal relationships between consecutive periods are discussed. Eruptions are numbered as given in Table A1, where the starting time, duration, and amount of lava output are listed for 49 eruptions since 1972. The numbering follows Benard and Krafft (1986). The data are from Benard and Krafft (1986) up to the eruption \#10, and from Bachelery (1999) for \#11 through \#38, and from various observatory reports summarized by the director, T. Staudacher, for more recent eruptions. In Table A1, the path to PdC in the last column belongs to the area "Dolomieu-east", but is separately tabulated here to facilitate the discussion in the text.

\section{A1.1 Active period of phase 1 of cycle I (I-1A): Obser- vations}

This is the period from which Benard and Krafft (1986) start showing photos of eruptions with detailed description. It starts with the eruption \#1 on 1972/6/9 at the Borywest area and ends with the one in the Dolomieu crater on 1973/5/10.

The eruption \#1 occurred after the inactivity of 6 years on 1972/6/9 from three fissures at elevations between 2540 and $2200 \mathrm{~m}$ on the south side of Bory. The eruption site is close to the first eruption of cycle II (\#19) and that of cycle III (\#40), all of which belong to the Bory-west area. The eruption stopped during the night between June 10 and 11 , with the estimated lava output of $0.12 \mathrm{M}$ (million) cubic meters.

The eruption \#2 occurred around 1972/7/25 on the east side of the Dolomieu at elevations between 2200 and 1760 $\mathrm{m}$ from four segments of radial fissures. The lava flow front reached an elevation of $1050 \mathrm{~m}$ when the eruption stopped on August 17. The amount of lava erupted was estimated at 3 $\mathrm{M}$ cubic meters. The eruption site is at the eastern periphery of the Dolomieu-east area.

The eruption \#3 occurred on 1972/9/9 on the north side of the Dolomieu cone at an elevation $2100 \mathrm{~m}$, near the site of a minor eruption 2 days earlier. This site is located at the boundary of the Bory-west and the NE rift-zone area. The eruption stopped abruptly on September 27 after emitting $5 \mathrm{M}$ cubic meters of lava. It accompanied some explosive activities that produced Pele's hair.

The eruption \#4 started on October 10, 1972 and occurred from several sites distributed over an area south of the Dolomieu cone at elevations between 1800 and $1750 \mathrm{~m}$. They are located at the western periphery of the SE rift-zone. The eruption lasted for two months and produced $9.3 \mathrm{M} \mathrm{cu}-$ bic meters of lava.

The final eruption of this period occurred on 1973/5/10 at an elevation of $2380 \mathrm{~m}$ within the Dolomieu crator. It lasted until May 28 and covered a part of the floor of the Dolomieu crator with $0.6 \mathrm{M}$ cubic meters of lava. This eruption was not numbered by Benard and Krafft (1986), and was not included in Table A1.

In summary the period I-1A lasted for 12 months and produced 17.4 M cubic meters of lava. As shown in Table 1 , this is the lowest output of all active periods. The three main eruption sites, \#2, 3 and 4, are located in the peripheral part of the Dolomieu-east, NE rift-zone, and SE rift zone, respectively.

\section{A1.2 Active period of phase 1 of cycle I (I-1A): Model- ing}

This period is similar to the period III-1A in being preceded by a long period of inactivity. The mode of eruption, however, is quite different. In III-1A, the Bory-west eruption and the beginning of eruption from fissures close to the summit was nearly simultaneous, while in this period, there is an interval of 11 months between the Bory-west eruption (June, 1972) and the first summit eruption (May, 1973). Furthermore, all three eruptions between the two occurred in peripheral parts of the Dolomieu-east, NE rift-zone and SE rift-zone. Combined with the fact that this period produced the lowest lava output of all active periods, we infer that the magma system of the volcanic edifice sketched in Fig. 2 was not developed fully during this period. Because of the underdeveloped system, the new magma arrived in June, 1972 had to overcome many barriers before reaching the summit crater. If we had the monitoring network then, we could have recorded the upward migration of the volcano-tectonic (VT) events lasting for 11 months in a manner similar to those observed during the 1 1/2 day preceding the March, 1998 eruption of III-1A. We could have, then, come up with a clearer picture of how the system developed. Unfortunately, the observatory was installed in 1980, and the first eruption observed instrumentally was \#14 in the period I-2Q.

When the system is well developed, magma channels may have no barriers, and there may be no VT activity associated with breaking barriers. The known absence of the upward migration of VT events associated with the new arrival of magma during II-1A, II-2A and III-2A may be attributed to the better developed magma system than during III-1A.

The end of the eruption \#3 was described as abrupt (brutalement). As we shall see later the mode of ending of an eruption appears to reflect how the lava is supplied to the eruption site. When an eruption occurs from an isolated magma patch such as postulated by Lénat and Bachélery (1990) due to the pressure increase by degassing, the eruption will be ending gradually with the decrease in the pressure. On the other hand, if the eruption site is connected to 
Table A1. List of the duration (days) and amount of lava (million cubic meters) for eruptions since 1972 classified according to the eruption areas defined in Fig. 1.

\begin{tabular}{|c|c|c|c|c|c|c|c|}
\hline No & Starting date & Duration in days & Bory-west & Dolomieu-east & NE rift-zone & SE rift-zone & To PdC \\
\hline 1 & $1972 / 6 / 9$ & 2 & 0.1 & & & & \\
\hline 2 & $1972 / 7 / 25$ & 24 & & 3 & & & \\
\hline 3 & 1972/9/9 & 19 & & & 5 & & \\
\hline 4 & $1972 / 10 / 10$ & 62 & & & & 9.3 & \\
\hline 5 and 6 & $1975 / 11 / 4$ & 15 & & 0.9 & & & \\
\hline 7 & $1975 / 12 / 18$ & 39 & & 1.3 & & & \\
\hline 8 & $1976 / 1 / 12$ & 19 & & & & 3.8 & \\
\hline 9 & $1976 / 1 / 29$ & 61 & & & & 6 & \\
\hline 10 & $1976 / 11 / 2$ & 2 & 0.3 & & & & \\
\hline 11 & $1977 / 4 / 5$ & 12 & & & 12 & & \\
\hline 12 & $1977 / 10 / 24$ & 24 & & 23 & & & \\
\hline 13 & 1979/7/13 & 1 & 0.3 & & & & \\
\hline 14 & $1981 / 2 / 3$ & 18 & 3 & & & & \\
\hline 15 & $1981 / 2 / 26$ & 32 & 4 & & & & \\
\hline 16 & $1981 / 4 / 1$ & 35 & & & & & 5 \\
\hline 17 & $1983 / 12 / 4$ & 46 & 8 & & & & \\
\hline 18 & 1984/1/18 & 32 & 9 & & & & \\
\hline 19 & $1985 / 6 / 14$ & 1 & 1 & & & & \\
\hline 20 & $1985 / 8 / 5$ & 27 & & & 7 & & \\
\hline 21 & 1985/9/6 & 36 & & 14 & & & \\
\hline 22 & $1985 / 12 / 1$ & 1 & & 0.7 & & & \\
\hline 23 & $1985 / 12 / 29$ & 41 & & 7 & & & \\
\hline 24 & $1986 / 3 / 19$ & 13 & & & & 14 & \\
\hline 25 & $1986 / 3 / 29$ & 270 & & 2.5 & & & \\
\hline 26 & 1987/1/6 & 36 & & & & & 10 \\
\hline 27 & 1987/6/10 & 20 & & 1.5 & & & \\
\hline 28 & 1987/7/19 & 2 & & 0.8 & & & \\
\hline 29 & $1987 / 11 / 6$ & 3 & 1.6 & & & & \\
\hline 30 & 1987/11/30 & 33 & & 10 & & & \\
\hline 31 & 1988/2/7 & 56 & & 8 & & & \\
\hline 32 & $1988 / 5 / 18$ & 76 & & 15 & & & \\
\hline 33 & $1988 / 8 / 31$ & 57 & 7 & & & & \\
\hline 34 & 1988/12/14 & 16 & & & 8 & & \\
\hline 35 & $1990 / 1 / 18$ & 2 & & 0.5 & & & \\
\hline 36 & $1990 / 4 / 18$ & 21 & & & & 8 & \\
\hline 37 & $1991 / 7 / 19$ & 2 & & 2.8 & & & \\
\hline 38 & $1992 / 8 / 27$ & 28 & & 5.5 & & & \\
\hline 39 & 1998/3/9 & 196 & & & 60 & & \\
\hline 40 & 1998/3/12 & 21 & 1 & & & & \\
\hline 41 & 1999/7/19 & 13 & & 1.8 & & & \\
\hline 42 & $1999 / 9 / 28$ & 26 & & 1.5 & & & \\
\hline 43 & $2000 / 2 / 14$ & 19 & 4 & & & & \\
\hline 44 & $2000 / 6 / 23$ & 37 & & 6 & & & \\
\hline 45 & $2000 / 10 / 12$ & 32 & & 9 & & & \\
\hline 46 & $2001 / 3 / 27$ & 8 & & 4.8 & & & \\
\hline 47 & $2001 / 6 / 11$ & 26 & & 9.5 & & & \\
\hline 48 & $2002 / 1 / 5$ & 12 & & & 12.5 & & \\
\hline 49 & $2002 / 11 / 16$ & & & & & & \\
\hline
\end{tabular}


a main magma channel, there is a possibility of diversion to other paths than the one connected to the current eruption site. The abrupt ending of \#3 suggests that the source of lava is not the old magma in an isolated patch left over from the earlier cycle, but the new magma arrived at the time of \#1. This is similar to what happened during the period III-2A as described in A11.1.

If the diversion of magma is from the summit path to the rift-zone path, we observe a swarm of LP events when a summit eruption stops abruptly as in II-1A and III-2A during which, we believe, that the shallow part of the magma system was well developed. As mentioned earlier the new magma has not reached the Dolomieu crater at the time of \#3, and the magma system was probably not developed. If so we should not observe any LP events associated with the end of \#3. If that were the case, the diversion might be due to an intrusion accompanied by a swarm of VT events. Thus the monitoring of both VT and LP events is important to find the condition of the magma system.

\section{A1.3 Active period of phase 1 of cycle I (I-1A): Cause} and effect

This period followed the 6-year period of inactivity after May, 1966, preceded by an active period involving a major oceanite eruption of $62 \mathrm{M}$ cubic meters in the NE rift zone in April, 1961. The large output in the last active period followed by the long period of inactivity is consistent with the under-developed magma system in this period. As we shall discuss in A2.2, the shallow magma system as sketched in Fig. 2 might be operative in the period I-1Q. If so, its development took at least a year after the arrival of new magma signaled by the eruption \#1.

\section{A2.1 Quiet period of phase 1 of cycle I (I-1Q): Obser- vations}

This period starts with 29 months of inactivity preceding the eruption \#5 and \#6 from two separate sites in the southern floor of the Dolomieu crater. It started on 1975/11/4 and, according to Benard and Krafft (1986), accompanied some earthquakes and minor collapses of the crater wall in the night of November 14. The lava lake formed by the eruption disappeared on November 18, marking the end of eruption with the total output of $0.9 \mathrm{M}$ cubic meters.

The eruption \#7 occurred on 1975/12/18 at elevations between 2115 and $2020 \mathrm{~m}$ in the Dolomieu-east area. It lasted until $1976 / 1 / 25$ with the total lava output of $1.3 \mathrm{M}$ cubic meters. While it is still active, the eruption \#8 occurred on $1976 / 1 / 12$ in the SE rift-zone at a low elevation of $1490 \mathrm{~m}$. The lava flow from \#8 reached Route Nationale 2 on January 27 . The eruption stopped on January 30 with the total output of $3.8 \mathrm{M}$ cubic meters.

The eruption \#9 started on 1976/1/29 nearly simultaneous with the end of \#8 at an elevation of 1780 in the SE rif-zone about midway between \#7 and \#8. It lasted until 1976/2/25 with the output of about $6 \mathrm{M}$ cubic meters.

A2.2 Quiet period of phase 1 of cycle I (I-1Q): Modeling

The occurrence of collapse on the floor of the Dolomieu crater as well as two significant eruptions from the SE riftzone indicate that the magma system in the volcanic edifice is well developed in this period. Since there was no supply of new magma from the mantle during this period according to our model, the eruption is attributed to the increase in pressure in some of the Lenat-Bachelery patches. Then we should not observe an abrupt ending of eruption. In fact, the description of Benard and Krafft on these eruptions suggests that they last long without sudden endings.

This period is similar to the early part of the period II-2Q in that both summit and rift-zone eruptions occurred. Since the initial model of the Piton de la Fournaise constructed by Aki and Ferrazzini (2000) explained various observations during the period II-2Q, we believe that the basic elements of the model sketched in Fig. 2, namely, deep NTR and NCR reservoirs, separate path of magma to the summit and the riftzone, and the LP source connected to the rift-zone in addition to the Lenat-Bachelery patches are operative also in this period. This could have been confirmed using observations on LP seismicity if we had a monitoring network then.

The collapse in the Dolomieu crater has been reported only three times since 1972 . They are associated with eruptions \#5-6 (the first eruption of I-1Q), \#24 (the last eruption of II-1A) and \#49 (the first eruption of III-2Q). They are all in the transient period from an active period to a quiet period. In all cases, the shallow magma system in the volcanic edifice is well developed. We have some evidence that the shallow magma system was not developed well in transition periods II-2A to II-2Q, and III-1A to III-1Q. For the remaining one, from I-2A to I-2Q, we have a well developed system for its rift-zone part, but not for the part connected to the Dolomieu crater. We shall come back to this point in discussions of each period because of the important societal impact of the collapse phenomena which are sometimes accompanied by phreatic explosions.

\section{A2.3 Quiet period of phase 1 of cycle I (I-1Q): Cause and effect}

The widely spread eruption sites in the NE and SE riftzones and the Dolomieu-east area during this period shows that the shallow magma system has become well developed. It followed the active period I-1A of 1-year duration in which the newly arrived magma reached the summit crater. It is followed by the active period I-2A in which the eruption occurs along the NE rift-zone outside the Enclos caldera for the first time since 1832 (Stieltjes and Moutou, 1989), suggesting that the shallow magma system as depicted in 2.2 was developed to the extent facilitating the newly arrived magma to cross the boundary of the Enclos caldera. As we shall see later, the eruption of March, 1986 which went outside the Enclos occurred also during the period in which the shallow magma system is well developed.

\section{A3.1 Active period of phase 2 of cycle I (I-2A): Obser- vations}

The eruption \#10 on 1976/11/2 in the Bory-west area marks the beginning of this period. It occurred in the northern part of the area where the events marking the beginning of the phase 2 of all three cycles cluster. It stopped next day with the estimated lava output of $0.3 \mathrm{M}$ cubic meters.

On 1977/4/5 an eruption fissure opened in the NE riftzone at an elevation of $1950 \mathrm{~m}$ near the northern boundary of Enclos caldera. The eruption stopped on April 7 with a small amount of lava output. A new fissure was opened on April 8 along the NE rift-zone outside the Enclos at an elevation of $1000 \mathrm{~m}$. More eruption fissures appeared along the riftzone toward the ocean, and the front of the lava flow reached 
the ocean on April 10. The whole episode of this eruption was short and the volcano became quiet on April 15. The estimate of the lava output varies greatly. Benard-Krafft's (1986) estimate is more than $100 \mathrm{M}$ and Stieltjes and Moutou (1989) gives $95 \mathrm{M}$, while Bachelery (1999) gives only $12 \mathrm{M}$. We adopted the last estimate in Table A1. We shall find in the next section that this choice of estimate is compatible with our model, but the others are not.

The eruption \#12 occurred on 1977/10/24 in the Dolomieu-east area at elevations between 2200 and $2050 \mathrm{~m}$. It stopped abruptly on November 16 with the lava output of $23 \mathrm{M}$ cubic meters.

\section{A3.2 Active period of phase 2 of cycle I (I-2A): Model- ing}

The most important question for this period concerns the order of magnitude difference in the estimation of the lava output for \#11 among the observers. If we adopt the estimate of $12 \mathrm{M}$ by Bachelery (1999), we obtain a remarkably constant amount in the L-B patches at the beginning of all the active periods as shown in Table 1. They are, 0 , $31,22,21,14$, and $11 \mathrm{M}$ cubic meters in the chronological order. They are obtained under the assumptions that (1) there was no residual magma in the beginning of I-1A, and (2) each new arrival brings $60 \mathrm{M}$ from the mantle. (A slight decreasing trend with time can be removed if we assume a slightly larger amount for each new arrival.) If we adopted the estimate of $100 \mathrm{M}$ for the erupted lava of \#11, we must make a drastic adjustment to our assumptions. The residual magma in the beginning of I-1A must be at least $60 \mathrm{M}$ or the supply from the mantle in cycle I-2A was at least 120 M instead of 60 M. In fact, Lénat and Bachélery (1990) hypothesize that all the eruptions after 1977 to the early part of the 1998 eruption were from the magma stored in 1977. This means that the amount of magma arrived in the period I-2A was more than $200 \mathrm{M}$ and there were no new magma arrival in cycle II. If this variable supply were true, a longterm prediction of the future eruption for Piton de la Fournaise would be impossible. On the other hand if our model of regularly repeated supply is valid, we have a great potential for predicting the future activity. In any case Bachelery's (1999) estimate of $12 \mathrm{M}$ output for the eruption \#11 permits our model with an exactly constant (60 M each) supply and roughly constant amount of residual magma at the beginning of all the active periods. The lack of significant long-term deformations before the eruption was one of the reasons for the Lenat-Bachelery model. The steady supply of relatively small amount of magma and nearly constant residual magma may be an alternate way to explain the observed lack of the precursory deformation. In fact, there was no detectable deformation even before the 1998 eruption, which clearly involved a supply of new magma (see Aki and Ferrazzini, 2001).

An interesting characteristic of the eruption \#12 is its sudden ending. In general the ending of eruptions from an isolated patch is expected to be gradual as discussed in A1.2, and the abrupt ending may mean a connection to the main magma system in which a sudden diversion of flow can take place. The abrupt ending can also be caused by blocking of flow due to some sudden collapse along its path. In A2.2, we attributed the lack of collapse in the Dolomieu crater after this active period to the under-developed magma system for the part connected to the crater.

\section{A3.3 Active period of phase 2 of cycle I (I-2A): Cause and effect}

An important aspect of this period is the eruption outside Enclos. The rapid manner in which magma proceeded to the ocean along the NE rift-zone suggests that the subsurface channel was more or less in place when the new magma arrived. This is consistent with the well-developed shallow magma system in the preceding period described in A2.2.

\section{A4.1 Quiet period of phase 2 of cycle I (I-2Q): Obser- vations}

This 91-month period produced the largest lava output of all the quiet periods as shown in Table 1 . The mode of eruption was also unique. All the eruptions except \#16 are from the Bory-west area. The eruption \#16 is from a fissure $700 \mathrm{~m}$ long oriented N70E at a location eastward from Dolomieu toward the Piton de Crac at elevations between 1930 and $1650 \mathrm{~m}$. This location is shared by the eruption \#26 in the period II-1Q, but is isolated from other eruptions either in the Dolomieu-east or NE rift-zone. We shall call this site "To Piton de Crac" as listed in Table A1.

The second eruption in this period, \#14 on 1981/2/3, is the first eruption after the establishment of the monitoring network at Piton de la Fournaise by the IPGP. Starting on January 23 , VT earthquakes originating at depths $1-3 \mathrm{~km}$ below the Bory crater were observed and the total number reached 73 by February 2 (Benard and Krafft, 1986). The seismicity increased one hour before the eruption ( 250 events recorded), marking the first observation of the "seismic crisis". All eruptions occurred in this volcano since then showed similar precursory seismic crises. A systematic relation was found later by Aki and Ferrazzini (2000) between the duration of the seismic crisis and the elevation of the eruption site from observations on eruptions \#22 through \#38 in cycle II. The observed relation for some eruptions in this period fit well the empirical relation for cycle II as for \#17 and \#18, but there are some others that do not. For example, the observed duration of 2 hours reported by Benard and Krafft for \#16 would predict the elevation in the range 2300 to $2000 \mathrm{~m}$ while the actual elevation was $1930-1650 \mathrm{~m}$.

The eruption \#14 is also the first eruption in which the concurrence of the beginning of eruption and the beginning of strong continuous tremor with dominant frequency 2 to 3 $\mathrm{Hz}$ was recognized. Since then all eruptions observed in the field confirmed this concurrence and the continuous tremor has been called the eruption tremor. The origin of tremor determined from its amplitude distribution agrees well with the eruption site.

Thus both the precursory swarm of VT events and the eruption tremor appear consistently for all eruptions at this volcano, but the occurrence of LP events does not. This is the reason why no emphasis was placed on the LP events in early seismological studies of this volcano, but is also the reason why it has become an important indicator of the changing condition of the magma system. As far as the records left on the shelves of the observatory are concerned, we could not find any LP events clearly associated with eruptions until \#20 in the period II-1A.

None of the eruptions in this period was described as 
ending abruptly.

A4.2 Quiet period of phase 2 of cycle I (I-2Q): Modeling

One of the basic assumptions underlying our model is that there is no supply of magma from the mantle during any quiet period. Thus the lava flow coming from the Borywest area in this period must be supplied from the residual magma in the L-B patches. The shallow magma system consisting of the Dolomieu-east and the two rift-zone must be closed for some reason. This is consistent with the gradual ending of the eruption as well as the apparent lack of LP events. Furthermore according to Benard and Krafft (1986), the two eruptions \#17 and \#18 overlap, the former ending on $1985 / 1 / 23$ and the latter starting on 1985/1/18 suggesting separate sources for them. This leads us to infer that the site of the eruption \#16, the only one outside the Bory-west area during this period, is not connected to the LP source and cannot be from the rift-zone path as defined in our model depicted in Fig. 2. The location of \#16 is isolated form other eruptions, justifying such an idea, which is also supported by the situation of only one other eruption sharing the same site, namely, \#26 as discussed in sections related to the period II$1 \mathrm{Q}$.

The above sequence of 5 eruptions from the Bory-west produced the total output of $24 \mathrm{M}$ cubic meters, and is followed by the June 14, 1985 eruption identified as the beginning of cycle II, and then by an exceptional seismic crisis called "east flank crisis" on July 10-11, 1985. This crisis was not followed by an immediate eruption and did not occur below the central cone as usual. It was unusual also in the range of their focal depths from $1 \mathrm{~km}$ b.s.l. down to $6 \mathrm{~km}$ b.s.l.. Lenat et al. (1989) attributed this crisis to the stress induced by intrusion of magma into the fracture system associated with the preceding series of eruptions in the Borywest area. A similar explanation was given by Zlotnicki et al. (1990) for the displacement vectors obtained by photogrammetric areal surveys made in 1981 and 1983 in the middle of the period I-2Q. These explanations are consistent with our model of residual magma, in which the pressure is increasing by degassing, seeking a way out through the Bory-west path because of the closure of the shallow part of the magma system.

\section{A4.3 Quiet period of phase 2 of cycle I (I-2Q): Cause and effect}

What is the cause of the long closure of the shallow magma system hypothesized above? In A3.2 we defined the closure period as starting with the end of eruption \#5 and \#6 in November, 1975, but the actual beginning could be the end of the eruption \#12 in November, 1977, which produced a large amount $(23 \mathrm{M})$ of lava flow and stopped suddenly. We have so far associated the sudden ending to the diversion of flow to another path which is suddenly opened, but we may also associate it with a sudden closure of the path supplying the lava blocked perhaps by some collapse along the path. Unfortunately, there was no monitoring network operating at that time to confirm this possibility.

As described in the following sections, the shallow magma system reopened with the NE rift-zone eruption (\#20) on $1985 / 8 / 5$, which included a swarm of LP events during the precursory seismic crisis in agreement with our model.

\section{A5.1 Active period of phase 1 of cycle II (II-1A): Obser- vations}

This period starts with the Bory-west eruption (\#19) on $1985 / 6 / 14$ and ends with the SE rift-zone eruption (\#24) outside Enclos accompanied by a pit crater formation in the floor of the Dolomieu crater on 1986/3/29. It lasted for 10 months and produced the total amount of $43.7 \mathrm{M}$ cubic meters of lava as shown in Table 1.

The eruption \#19 was from a fissure on WSW of the Bory crater at elevations between 2540 and 2250, lasted only for one day and stopped gradually as is usually the case for an eruption from the Bory-west area. It was preceded by a seismic crisis of less than 1 hour duration consisting of shallow VT events beneath the summit. There were no LP events associated with this eruption.

There was a swarm of shallow VT events beneath the summit on 1985/7/9 with no accompanying eruption. This is the first seismic crisis without eruption observed here since the establishment of the monitoring network and was interpreted as a dynamic intrusion of magma without reaching the surface. On the next day a vigorous swarm of VT events called "east flank crisis" started ENE of the summit at depths of 1 to $6 \mathrm{~km}$ b.s.l. as mentioned in A4.2. This crisis surpassed the previous crises beneath the summit by two orders of magnitude in the number of earthquakes as well as the energy released.

The eruption \#20 occurred on 1985/8/5 in the NE rift zone. A swarm of 13 unmistakable LP events with dominant frequencies around $1 \mathrm{~Hz}$ was found during its precursory seismic crisis. The eruption lasted for 26 days with the lava output of $7 \mathrm{M}$ cubic meters. The duration of the precursor crisis measured on the Sefram record was 2 hour $37 \mathrm{~min}$. which, together with the elevation of the eruption site (2100-2000 $\mathrm{m})$ contributed to the empirical systematic relation between the elevation and the duration of seismic crisis obtained for 13 eruptions occurred from 1985 through 1992 as shown in figure 8 of Aki and Ferrazzini (2000). The ending of \#20 was not abrupt.

The eruption \#21 occurred on 1985/9/6 from three fissures including one running within the Dolomieu crater. After September 7, the eruptive activity was limited to the fissure on the east flank. The eruption stopped on October 10 with the total output of $17 \mathrm{M}$ cubic meters. LP events with a dominant frequency of about $1 \mathrm{~Hz}$ were recorded during the first few days of the eruption.

The eruption \#22 occurred on 1985/12/2 from a $2 \mathrm{~km}$ long fissure on the south flank. It was short lasting for 28 hours with the lava output of about $1 \mathrm{M}$. It was immediately followed by a swarm of 20 LP events with a dominant frequency of about $1 \mathrm{~Hz}$. We classify this eruption to the Dolomieu-east area although it is at the boundary with the Bory-west area, because the southern end of the eruption fissure is located closer to the Dolomieu-east area. The choice of the Borywest path would contradict our interpretation of LP events following the end of eruption.

The eruption \#23 started on 1985/12/29 from a fissure in the Dolomieu crater and covered $95 \%$ of the crater floor by the time when the eruption stopped on 1986/2/2 with the total lava output of $7 \mathrm{M}$ cubic meters.

The eruption \#24 was preceded by a seismic crisis of 9 
hour 24 min. duration which included a swarm of LP events with dominant frequency around $1 \mathrm{~Hz}$. The eruption started on 1986/3/19 in the SE rift-zone at an elevation of $1750 \mathrm{~m}$ but lasted only for 9 hours with the lava output of $0.5 \mathrm{M}$. Next day, a new fissure opened at Takamaka in the same riftzone outside the Enclos caldera producing lava flow which reached $200 \mathrm{~m}$ from the coast. On 1986/3/23, an eruption started near the Pointe de la Table further along the same rift-zone preceded by a swarm of LP events with a dominant frequency of about $1 \mathrm{~Hz}$ originating beneath the summit. The effusive activity at Pointe de la Table stopped on 1986/4/1 with the output estimated at 3-5 M cubic meters. In the meantime, the seismicity at the summit became exceptionally intense on 1986/3/28 which culminated as a pit crater formation in the Dolomieu crater on the next day accompanied by phreatic explosions. The pit crater was $150 \mathrm{~m}$ in diameter and $80 \mathrm{~m}$ deep.

\section{A5.2 Active period of phase 1 of cycle II (II-1A): Mod- eling}

The abundant LP events directly associated with individual eruptions during this period indicate that the shallow magma system is well developed. We find eruptions from the Dolomieu-east as well as both rift-zones. The path to the Dolomieu crater is open and $95 \%$ of the crater floor was covered by the lava erupted during this period. The rapid manner the eruption \#24 extended outside the Enclos along the SE rift-zone suggests that the magma path was already in place at the time of its occurrence just as in the case of \#11 in the NE rift zone in 1977. The formation of a pit crater in the Dolomieu floor near the end of \#24 implies that the summit path is connected to the SE rift-zone during this period.

The occurrence of LP events with the dominant frequency of $1 \mathrm{~Hz}$ during the precursory crisis of \#20 (NE rift-zone) and \#24 (SE rift-zone) indicates that the connection to the rift-zone was through the source of $1 \mathrm{~Hz}$ LP events. Their absence before \#22 (Dolomieu-east) but their occurrence immediately following it shows that the stopping of the eruption \#22 is caused by the diversion of magma flow from the summit path to the rift zone path. The absence of LP events associated with \#19 (Bory-west) shows that the LP source is not connected to the Bory-west path. The eruptions during this period contributed to the data from which Aki and Ferrazzini (2000) recognized the separate paths for the summit and rift-zone eruptions and the location of LP source as shown in Fig. 2.

\section{A5.3 Active period of phase 1 of cycle II (II-1A): Cause and effect}

This period follows the 8-10 year closure of the path to the Dolomieu crater discussed in A4.2 and 4.3. With the new arrival of magma concurrent with \#19, the pressure and temperature were increased, and the path was reopened. Then a seismic crisis beneath the summit occurred on 1985/7/9 without eruption and was followed by the vigorous east-flank crisis which has been the only such crisis observed since the establishment of monitoring network. We agree with the interpretation by Lenat et al. (1989) that this crisis represents the release of compressional stress accumulated in the central area of the volcano during the repeated intrusions occurred over several preceding years. This crisis may also be related to the opening of the path to the shallow magma system closed for $8-10$ years, because it was followed immediately by \#20 (1985/8/5) in the NE rift zone and \#21 $(1985 / 9 / 6)$ in the Dolomieu-east area with the first lava flow within the Dolomieu crater since November, 1975. Both eruptions are accompanied by a swarm of LP events, indicating that the LP source was also quickly established.

Thus we see here a quick development of the shallow magma system within a few months once a blocking barrier in the flow path is removed. The arrival of new magma into the well-developed shallow magma system resulted in the lava flow outside the Enclos caldera during the eruption \#24 in the SE rift-zone.

\section{A6.1 Quiet period of phase 1 of cycle II (II-1Q): Obser- vations}

This period follows the pit crater formation on 1986/3/29 and ends with the arrival of new magma signaled by the eruption \#29 on 1987/11/6 in the Bory-west area. It lasted for 19 months and produced the total lava output of 16.9 $\mathrm{M}$ cubic meters. After the formation of the pit crater, the lava remaining from the eruption \#23 which filled $95 \%$ of the Dolomieu floor fell back into the pit crater as a $5 \mathrm{~m}$ wide cascade until April 5. Several minor eruptions from fissures in and near the pit crater occurred until 1987/1/6 with the total lava output of $2.5 \mathrm{M}$ cubic meters. As soon as the eruption in the Dolomieu crater stopped, the eruption \#26 began on the same day from the site we called "To Piton de Crac" in A4.1, where the eruption \#16 from the same site is attributed to a magma path not connected to the NE rift zone. The concurrence of the stopping of the eruption in the Dolomieu crater and the beginning of \#26 as well as the absence of LP events associated with \#26 further supports that this site does not belong to the NE rift-zone path. This eruption ended gradually sometime between 6 and 10 February, 1987 with the lava output of $10.5 \mathrm{M}$ cubic meters.

The eruption \#27 on 1987/6/10 was again from the floor of the Dolomieu crater. It lasted for 20 days with the lava output of 1.5 M cubic meters. The last eruption (\#28) in this period occurred at two separate sites in the Dolomieu-east area at about the same elevation around $2000 \mathrm{~m}$. It lasted 2-3 days with the lava output of $0.8 \mathrm{M}$ cubic meters.

We observed a swarm of large LP events with dominant frequencies 1 to $1.5 \mathrm{~Hz}$ between mid-February and midMarch, 1987 with no direct relation with the eruptive activity. Otherwise the LP seismicity beneath the summit was relatively low as compared with the preceding period (II-1A). The low LP seismicity persisted through 1988 nearly to the end of the next active period (II-2A) when the eruption \#34 occurred on 1988/12/14 in the NE rift-zone preceded by a swarm of LP events.

As described in Aki and Ferrazzini (2000), we observed numerous LP events with a dominant frequency of $3.5 \mathrm{~Hz}$ recorded only at station NCR (now moved nearby NSR) in 1987, particularly frequently from June to September. Their sharply peaked spectra suggested a seismic source of an isolated magma pocket with high impedance contrast. Their occurrences also had no direct relation with the eruptive activity. 
A6.2 Quiet period of phase 1 of cycle II (II-1Q): Modeling

The above observations suggest an intermediate development of the shallow magma system in this period. The absence of rift-zone eruption and the low level of LP seismicity indicate that the rift-zone part of the system was not as well developed as in the preceding period (II-1A). The magma path along the rift zone may be not continuous but broken into segments.

The occurrence of LP events unrelated with eruptions appears to be common during the quiet period as we shall find more examples in the period II-2Q. If the rift-zone path is segmented, we can explain LP events unrelated with eruptions as magma movements between segments. We did not observe any LP during the period I-2Q because the shallow magma system was closed at that time.

\section{A6.3 Quiet period of phase 1 of cycle II (II-1Q): Cause and effect}

This period follows the spectacularly active period with eruptions outside the Enclos caldera and a pit crater formation in the Dolomieu crater, attributed to a well-developed shallow magma system. It is followed by an active period in which there was no rift-zone eruption until its end, nor any collapse in the Dolomieu crater and the two largest eruptions ended gradually as described in A7.1, making a strong contrast to the other active periods (I-2A and II-1A) in which the new magma arrived when the shallow magma system is well developed. The difference may be attributed to the intermediate degree of development of the shallow magma system with segmented path during this period. The segmented system may also explain the gradual ending of some eruptions in the next period.

\section{A7.1 Active period of phase 2 of cycle II (II-2A): Obser- vations}

This period starts with the eruption \#29 on 198711/16 in the Bory-west area and ends with the eruption \#34 on $1988 / 12 / 14$, producing the total lava output of about $50 \mathrm{M}$ cubic meters. The eruption \#29 occurred at two sites separated by $1.5 \mathrm{~km}$ near the north end of the Bory-west area where the other two eruptions (\#10 and \#43) marking the beginning of phase 2 also occurred. It lasted for three days and produced the lava output of $1.6 \mathrm{M}$ cubic meters.

The eruption \#30 occurred on 1987/11/30 in the Dolomieu-east area starting with a fissure at elevation 2240$2080 \mathrm{~m}$ on the south side of Dolomieu followed by those at elevations around $1900 \mathrm{~m}$. It lasted for 33 days and produced $10 \mathrm{M}$ cubic meters. The ending of this eruption was very gradual with intermittent tremors sometimes interrupted for 30 minutes. The low tremor amplitude lasted for 7 days before the end of eruption. The eruption was preceded by the usual seismic crisis composed of shallow VT events beneath the summit, but there were no concurrent LP events before, during or following it.

The eruption \#31 occurred on 1988/2/7 near the site of \#30 and lasted for 56 days with the lava output of $8 \mathrm{M}$ cubic meters. The ending of eruption was again extremely gradual, characterized by rhythmic amplitude fluctuation of the eruption tremor and a very low amplitude persisting for more than 10 days before the end of eruption. The duration of precursory seismic crisis was 2 hour 5 min. Again, we found no LP events associated with this eruption.

The eruption \#32 occurred on 1988/5/18 in the Dolomieueast area on the north side of Dolomieu. It lasted for 76 days with the lava output of $15 \mathrm{M}$ cubic meters. The ending of this eruption is again extremely gradual. The duration of the precursory seismic crisis was $31 \mathrm{~min}$. and there were no LP events associated with this eruption.

The above three eruptions are similar in their characteristic and produced the total amount of lava estimated at $33 \mathrm{M}$ cubic meters in 7 months. The elevation of the eruption site and the duration of the precursory seismic crisis from these eruptions contributed to the empirical relation between them shown in figure 8 of Aki and Ferrazzini (2000).

The eruption \#33 following the above sequence occurred on 1988/8/31 in the Bory-west area. It lasted for 57 days producing the lava output of $7 \mathrm{M}$ cubic meters. This is the only one in the Bory-west area since 1972 occurred in the middle of an active period. All others are either at the beginning of an active period or in the quiet period $\mathrm{I}-2 \mathrm{Q}$ during the 8-10 year period of the closure of the shallow magma system discussed earlier. We observed a sequence of gas piston events on 1988/10/26 when the eruption was ended. The precursory crisis lasted for 2 hour $25 \mathrm{~min}$., and again there were no LP events associated with the eruption.

The eruption \#34 occurred on 1988/12/14 in the NE rift zone from fissures at elevations $2100-2000 \mathrm{~m}$. A swarm of LP events with dominant frequencies around $2 \mathrm{~Hz}$ appeared during the precursory seismic crisis which lasted for 4 hour $31 \mathrm{~min}$. Unlike the usual summit eruption in which eruption fissures propagate downward, a new fissure opened above the older one during this rift-zone eruption. Unlike all the preceding eruptions of this period, this eruption stopped suddenly on 1988/12/29 followed by a swarm of LP events with a dominant frequency of $1 \mathrm{~Hz}$ lasting for a few days. The eruption lasted for 15 days with the lava output of $8 \mathrm{M}$ cubic meters.

There was no collapse in the floor of the Dolomieu crater during the transition to the quiet period following this active period. All the eruptions in this period were confined within the Enclos caldera.

\section{A7.2 Active period of phase 2 of cycle II (II-2A): Mod- eling}

The three major eruptions of this period are all in the Dolomieu-east area with gradual endings, which suggest an isolated magma reservoir supplying each eruption. The absence of LP events following these eruptions indicates the absence of connection between the eruption site and the rift zone. The occurrence of a Bory-west eruption following the above sequence must be due to a temporary closure of the shallow magma system, although there were no observed seismic events that might be associated with such a change in the system. After the Bory-west eruption, the rift zone part of the shallow magma system becomes suddenly well developed as indicated by the swarm of LP events in the precursory crisis of \#34 and its abrupt ending. Again there were no significant seismic events which might be associated with the system change, except for an increase of shallow VT seismicity after a swarm of duration $25 \mathrm{~min}$. on 1988/11/12 a month before \#34.

The above observations suggest a magma system with seg- 
mented path in an unstable condition. Thus major eruptions come from isolated patches and the magma path can be closed and opened suddenly without observable effects. Apparently under this condition of the magma system, there is no highly energetic phenomena such as the collapse in the Dolomieu crater or an eruption outside the Enclos.

Aki and Ferrazzini (2000) attributed the difference in dominant frequency of LP events before and after \#34 to two separate sources for $1 \mathrm{~Hz}$ and $2 \mathrm{~Hz}$ LP events. The magma was supplied to the eruption site of \#34 through the $2 \mathrm{~Hz} \mathrm{LP}$ source, but the eruption was stopped because the connection was made between the $1 \mathrm{~Hz}$ LP source and the eruption site and the magma was drained back to the $1 \mathrm{~Hz}$ source from the eruption site. The assumed two separate sources for $1 \mathrm{~Hz}$ and $2 \mathrm{~Hz} \mathrm{LP}$ events are also consistent with the difference in long-term change of their activities as discussed in A8.1.

\section{A7.3 Active period of phase 2 of cycle II (II-2A): Cause and effect}

Let us compare the present period with the other active period of phase 2. In the period I-2A, the 1977 eruption outside the Enclos occurred and we attributed it to the shallow magma system well developed already before the arrival of new magma. In the period III-2A which included a lava flow from the NE rift-zone reaching the ocean, we shall see that the development of the shallow magma system as indicated by the reactivation of LP activity is nearly simultaneous as the arrival of new magma. On the other hand, the shallow magma system in the present period at the time of arrival of new magma was in an intermediate state of development as indicated by generally low LP seismicity and occasional LP swarms unrelated to eruptions in the preceding period.

Following this period, we shall enter a period with an abundant occurrence of LP events both related and unrelated to eruptions. The revival of the $1 \mathrm{~Hz} \mathrm{LP}$ source following the eruption \#34 indicates the reappearance of the well developed shallow magma system which will persist through the period II-2Q until LP events gradually disappear as we enter the 6-year period without eruption.

\section{A8.1 Quiet period of phase 2 of cycle II (II-2Q): Obser- vations}

We note the similarity of eruption sites during this period with those in periods I-1Q and II-1A. In all three cases an SE rift-zone eruption was preceded by an eruption inside the Dolomieu crater.

This period starts with the eruption \#35 which occurred on 1990/1/18 from a fissure in the Dolomieu crater which propagated southward outside the crater. The eruption was short and stopped next day with the lava output of $0.5 \mathrm{M}$ cubic meters, covering $20 \%$ of the Dolomieu crater floor. It was preceded by a swarm of VT events with a duration of 47 $\min$.

The LP seismicity showed a remarkable increase in 1989 ( 76 events with dominant frequency 1 to $3 \mathrm{~Hz}$ ) although there was no eruption during the year. We observed a swarm of 10 small LP events in 4 days preceding \#35 and a large one with the dominant frequency of $1 \mathrm{~Hz}$ immediately following it.

The eruption \#36 occurred on 1990/4/18 in the SE rift zone at an elevation of $1800 \mathrm{~m}$. The long duration of the seismic crisis (6 hour $45 \mathrm{~min}$.) for this low elevation contributed to the systematic relation between the duration and elevation mentioned earlier. A swarm of LP events was observed during the crisis. It lasted for 21 days with the lava output of $8 \mathrm{M}$ cubic meters. Its ending was gradual.

There was a major swarm of LP events during MarchApril, 1991 with no direct relation to any eruption. They are characterized by the dominant frequency of $1.4 \mathrm{~Hz}$, and their total number reached 110 when it was suddenly stopped concurrent with the arrival of seismic waves from a $M=5.8$ earthquake in Madagascar $800 \mathrm{~km}$ away from the Reunion island.

The eruption \#37 occurred on 1991/7/19 from a fissure at an elevation $2510 \mathrm{~m}$ along the southern edge of the Dolomieu crater, which extended toward the east flank of the volcano to an elevation of $2400 \mathrm{~m}$. It lasted for 2 days and produced the lava output of $2.8 \mathrm{M}$ cubic meters. The duration of its precursory seismic crisis was $52 \mathrm{~min}$. and there were no LP events associated with this eruption.

A major seismic crisis without a following eruption but with numerous LP events occurred on 1991/12/7 as described in detail by Aki and Ferrazzini (2000). A vigorous LP seismicity lasted for three weeks amounting to the total number of 320 events with dominant frequencies between 1 and $3 \mathrm{~Hz}$.

Last eruption of cycle II, \#38, occurred on 1992/8/27 starting from a fissure within the Dolomieu crater, which propagated rapidly southward outside the crater. Four additional vents opened on the south side of the summit down to the elevation $2100 \mathrm{~m}$. It lasted till 1992/9/23 with the lava output of $5.5 \mathrm{M}$ cubic meters. The duration of its precursory crisis was $57 \mathrm{~min}$. There was a swarm of LP events with dominant frequencies 1.1 to $1.5 \mathrm{~Hz}$ near the end of this eruption. After that, we have observed no LP events with dominant frequencies lower than $1.5 \mathrm{~Hz}$ for nearly 6 years till 5 hours before the major eruption on 1998/3/9.

The history of LP events originating beneath the summit of Piton de la Fournaise from 1985 to 1996 was summarized in a histogram of annual number of LP events with a given dominant frequency for the range between 0.8 to $3.0 \mathrm{~Hz}$ in figure 5 of Aki and Ferrazzini (2000). The most outstanding trend in the figure is the systematic disappearance of LP events after the eruption \#38. LP events with the lowest frequency disappeared first. Those with dominant frequencies around $2 \mathrm{~Hz}$ become dominant in 1993, decreased gradually and practically vanished in 1996. A $2 \mathrm{~Hz}$ LP event located beneath the summit reappeared on 1997/6/4. In the same figure we recognized a similar frequency-dependent disappearance of LP events from 1985-86 to 1987-88, when the LP seismicity declined from the period II-1A to the periods II-1Q and II-2A as described earlier.

The VT seismicity also decreased gradually after \#38, but the rate of their occurrence did not become zero like the LP seismicity. The rate for 1995 is about one half of that for 1993, and there was an indication of revival already in 1996. The first seismic crisis after \#38 occurred on 1996/11/26 without eruption.

\section{A8.2 Quiet period of phase 2 of cycle II (II-2Q): Mod- eling}

The well developed shallow magma system was maintained without any supply of new magma from the end of \#34 to the end of \#38, spanning 45 months, in which 4 erup- 
tions with total output of $17 \mathrm{M}$ cubic meters occurred in the Dolomieu-east and SE rift-zone area. This period is characterized by abundant LP events unrelated to individual eruptions. The vigorous seismic crisis of 1991/12/7 involving numerous LP events was not followed by an eruption, but must mean a significant magma movement through the rift-zone path. According to Battaglia (2000), the GEOSCOPE record of this crisis indicates an inflation of the summit area similar to what was observed in the beginning of the March, 1998 eruption (\#39), while eruptions \#38, \#41 and \#42 showed a deflation followed by inflation, as might be expected for eruptions from an isolated magma patch. My tentative explanation of the crisis of 1991/12/7 is that it was the last attempt of magma going into the rift-zone path during cycle II. It did not succeed and stayed in the volcano to come out as part of lava output of the March 1998 eruption.

At the time of writing of Aki and Ferrazzini (2000), we did not know about the concurrent change in the characteristics of eruption tremor and those of lava geochemistry two months after the beginning of the eruption \#39, which will require the presence of the old magma remaining in the shallow part of volcanic edifice as hypothesized by Lénat and Bachélery (1990). We estimate the amount of the remaining magma at the time of the beginning of the period III-1A as $14 \mathrm{M}$ cubic meters as shown in Table 1.

Thus the disappearance of LP events following the last eruption of the period II-2Q does not necessarily mean the disappearance of magma. We must conclude that magma can stay at the shallow part of a volcano (at about sea level) in an isolated patch without generating observable LP events for several years.

\section{A8.3 Quiet period of phase 2 of cycle II (II-2Q): Cause and effect}

It is interesting to compare the condition of the magma system between this period and the corresponding period of cycle I, namely, I-2Q during which the path to the shallow part of the magma system was blocked from its beginning until the new arrival of magma in II-1A, after which the shallow magma system was immediately well developed. In the present period the shallow magma system was well developed at its beginning, and gradually became segmented and finally inactive with some magma remaining quietly in isolated patches. It took more than 2 years after the arrival of new magma in the period III-1A before the shallow magma system become well developed as described in A11.1.

\section{A9.1 Active period of phase 1 of cycle III (III-1A): Ob- servations}

This period consists of two simultaneous eruptions \#39 and \#40. The eruption \#40 is from a vent named "Fred Hudson" in the southern part of the Bory-west area where the first events in cycle I and II are also originated. It started three days after \#39, lasted 21 days with the lava output of $1 \mathrm{M}$ cubic meters. The eruption \#39 was preceded by a seismic crisis of $11 / 2$ day duration in which the focal depth of VT events migrated from about $5 \mathrm{~km}$ below sea level to the surface near the summit. The eruption started on 1998/3/9 from a fissure on the north flank of the central cone at an elevation of $2450 \mathrm{~m}$, which propagated downward in an en echelon pattern, and became concentrated at two vents, named "Piton Kapor" and "Maurice and Katia Krafft", at an elevation of 2150 and $2080 \mathrm{~m}$, respectively. The eruption lasted for 6 months with the lava output of $60 \mathrm{M}$ cubic meters.

The vigorous seismic crisis of $11 / 2$ day duration was preceded by an increased VT seismcity beneath the summit at about sea level for about 7 months. As mentioned in A8.1 there was an indication of revival of VT events in 1996. Their focal depths ranged 10 to $30 \mathrm{~km}$, and the largest one with $M=2.5$ occurred on $1996 / 3 / 2$ at a depth of $15 \mathrm{~km} \mathrm{b.s.l.}$ a few kilometers east of the central cone. It was followed by a cluster of seven events with $M=1.6$ to 1.8 occurring at depths 16 to $18 \mathrm{~km}$ about $5 \mathrm{~km}$ northwest of the central cone in September, 1996 and by an $M=2.3$ event under station CHR (located also northwest of the central cone, now moved to nearby TCR) at a depth of $2 \mathrm{~km}$ b.s.l. Then we had the first seismic crisis since the eruption of August, 1992 occurred on 1996/11/26. This crisis consisted of 138 VT events located at about sea level beneath the central cone. The largest magnitude was 2.4, and the crisis lasted for 104 min. It was not followed by any eruption.

All the LP events originating beneath the summit before September, 1993 showed identical arrival times and very similar waveforms at the three summit stations (BOR, SFR and DSR), which we call "coherent". After September, 1993, we began to observe LP waves which did not show this coherence. All LP events in cycle II after January, 1994 showed different arrival times and incoherent waveforms at the three summit stations. The last LP event of the cycle II activity confirmed to originate from beneath the summit area occurred on 1995/4/1. It was incoherent and the dominant frequency was $2.6 \mathrm{~Hz}$. The first LP event of the cycle III activity confirmed to originate from beneath the summit was also incoherent and its dominant frequency was $2 \mathrm{~Hz}$. Thus the last disappearing is similar to the first reappearing. The 1 $\mathrm{Hz}$ LP event which disappeared after the eruption of AugustSeptember, 1992 reappeared about 5 hours before the eruption of March 9, 1998. Their waveforms at the three summit stations were incoherent. As we shall find later in the period III-2A, the first coherent LP event in cycle III appeared on 2000/2/8 with the dominant frequency of $4 \mathrm{~Hz}$, and the first large coherent LP events with the dominant frequency of 1 $\mathrm{Hz}$ appeared in November, 2000, 42 hours after the end of the eruption \#45 that stopped suddenly.

As reported by Aki and Ferrazzini (2000), the amplitude of the eruption tremor of \#39 showed a large fluctuation in the first two months and become nearly constant and smooth till the end of the eruption.

\section{A9.2 Active period of phase 1 of cycle III (III-1A): Mod-} eling

The crisis of 1996/11/26 was interpreted by Aki and Ferrazzini (2000) as the beginning of the filling of a reservoir named "NTR" in Fig. 2, located in the southern part of the Enclos caldera at the bottom of the volcanic edifice based on the observed spatial and temporal change in the coda localization. The 7 months period of increased VT seismicity preceding the eruption \#39 was interpreted by them as the period for filling the other deep reservoir named "NCR" beneath the northern part of the Enclos caldera. It took 15 months for the newly arrived magma to fill the two deep reservoirs with 60 $\mathrm{M}$ cubic meters according to their interpretation. The corre- 
sponding flow rate is 8.5 times higher than that of the steady supply to each of the two mantle reservoirs (655 cubic meters per hour) assumed by Cabusson (2002) for explaining the observed two phases of each cycle. The lava output of $60 \mathrm{M}$ for the eruption \#34 and its duration of 6 months give the average flow rate during the eruption 21 times that of the steady mantle supply.

The temporal regularity in the disappearance and appearance of different types of LP events let Aki and Ferrazzini (2000) postulate the source of coherent $1 \mathrm{~Hz}$ LP event at the shallowest depth beneath the summit underlain by that of the coherent $2 \mathrm{~Hz}$ LP event. The source of the incoherent LP event was placed not directly beneath the summit and probably deeper than those of the coherent ones.

LP events during this period were "incoherent" and scarce as in the following period III-1Q. We attribute them to the under-developed condition of the shallow magma system.

The similarity in the temporal behavior between the eruption tremor and the chemistry of lava during the eruption \#39 enabled a merging of two radically different earlier models of this volcano, namely the one by Aki and Ferrazzini (2000) and the other by Lénat and Bachélery (1990). The former assumes the existence of large magma reservoirs near the bottom of the volcanic edifice which supplied lava for the 1998 eruption, while the latter model consists of numerous small shallow reservoirs of magma filled in 1977 or earlier, which supplied lava for all eruptions after 1977 without any additional supply from below.

The observed irregular variation in chemical composition of lava in the first two months followed by a smooth systematic variation till the end of the eruption was interpreted by Bachelery (1999) as due to a mixing of old magma remaining since 1977 with the newly arrived one represented by the lava erupted from the "Fred Hudson" vent. Aki and Ferrazzini (2000) interpreted a similar temporal variation in the amplitude of seismic tremor as the change due to opening of connection between the eruption site and a reservoir of larger capacity. Thus it appears that the main part of the erupted lava came first from the old magma patches of Lenat and Bachelery (1990) somehow stimulated by the arrival of new magma at the summit, and it took two months before the mixing of new and old magma started and the eruption site was connected hydro-dynamically to large reservoirs located near the bottom of the volcanic edifice.

\section{A9.3 Active period of phase 1 of cycle III (III-1A): Cause and effect}

In A8.3 we compared periods I-2Q and II-2Q, and found a great difference between them in the manner in which the shallow magma system was developed. This difference is reflected in the different mode of eruption in the succeeding active period. The LP source beneath the summit was developed immediately with the new arrival in II-1A, but was not developed at all during III-1A and took two more years after the end of III-1A for its full development. We attributed the eruption outside the Enclos and the formation of pit crater collapse in the Dolomieu crater during II-1A to the well developed shallow magma system. Both are absent during III$1 \mathrm{~A}$, even though the total lava output was greater in III-1A than in II-1A (60 M vs $44 \mathrm{M})$.

\section{A10.1 Quiet period of phase 1 of cycle III (III-1Q): Ob- servations}

This quiet period generated the least lava output of all the quiet periods. The output was only $3.3 \mathrm{M}$ as compared to 12-34 $\mathrm{M}$ for the others. It also had the least estimate of the residual magma at its beginning, namely, $14 \mathrm{M}$ as compared to $26-56 \mathrm{M}$ for the others as shown in Table 1 . The two eruptions \#41 and \#42 in this period are both in the Dolomieueast area and both stopped gradually. They were preceded by the seismic crisis of VT events beneath the summit as usual. There were no LP events associated with them. There was no collapse in the floor of the Dolomieu crater in the transition period from the preceding active period.

\section{A10.2 Quiet period of phase 1 of cycle III (III-1Q): Modeling}

All the observations mentioned above indicates a poorly developed shallow magma system during this period. We note that the precursory swarm of VT events occurs more of less in the same way independent of the condition of the shallow magma system. This means that they are useful for a practical short-term prediction, but not for determining the condition of the magma system.

\section{A10.3 Quiet period of phase 1 of cycle III (III-1Q): Cause and effect}

The activity of this period is probably due to the small amount of magma left in the shallow part of the volcano because of the large amount of lava erupted during the preceding period. The amount of residual magma, however, was enough for developing the shallow magma system quickly after the arrival of new magma in the following period.

\section{A11.1 Active period of phase 2 of cycle III (III-2A): Observations}

This period starts with the eruption \#43 located in the northern part of the Bory-west area where the first eruption occurred also for phase 2 of both cycle I and II. Its singular location among others in this period attracted my attention and lead to the identification of the 13-year cycle of eruption history since 1972 as mentioned in the introduction. It occurred on 2000/2/14 and lasted for 19 days with the lava output of $4 \mathrm{M}$ cubic meters. Details of observations about this and the following eruptions were given in various observatory reports summarized by the director, T. Staudacher.

The eruption \#43 was preceded by 6 weeks of slightly enhanced seismicity of VT events beneath the summit with a mean of 5 events per day. The duration of the precursory seismic crisis was 64 min. in which 261 events occurred with magnitude up to 1.9 .

The eruption \#44 occurred on 2000/6/23 from several fissures on the ESE flank at elevations between 2080 and 1820 m. It lasted for 37 days with the lava output of $6 \mathrm{M}$ cubic meters. It was preceded by a dramatic increase of shallow VT seismicity starting in mid-June including a minor seismic crisis on June 22 . The precursory seismic crisis included 270 events with magnitude up to 2.5 . This eruption stopped gradually with no associated LP events.

The next three eruptions \#45, \#46 and \#47 all occurred from vents near \#44 in the Dolomieu-east area with the total lava output of $23.3 \mathrm{M}$ cubic meters. They are preceded by swarms of shallow VT events beneath the summit. These events were small in magnitude but showed unusually 
long durations for this volcano. All three eruptions stopped abruptly followed by swarms of LP events.

The eruption \#45 which started on 2000/10/12 was preceded by 3 weeks of high VT seismicity at a rate of 10-20 events per day. The largest magnitude was 1.7. The seismic crisis immediately before the eruption had 201 events with the largest magnitude of 1.6 and a duration of $64 \mathrm{~min}$. The eruption lasted for 37 days with the lava output of $9 \mathrm{M}$ cubic meters. The eruption tremor increased from October 29 to November 9 continuously and stayed constant for five days before disappearing suddenly on November 13 within $25 \mathrm{~min}$.

The eruption \#46, which started on $2001 / 3 / 27$, was preceded by three swarms of small shallow VT events beneath the summit starting January 20, February 25 and early March. The precursory crisis had 120 VT events and a duration of $25 \mathrm{~min}$. The eruption lasted for 8 days with the lava output of $4.8 \mathrm{M}$ cubic meters. The eruption tremor showed a slight increase before the end of eruption.

The eruption \#47 started on 2001/6/11 and lasted for 26 days with the lava output of $9.5 \mathrm{M}$ cubic meters. A swarm of small shallow VT events beneath the summit started on May 23 at a rate of 6 to 36 events per day. There was a minor seismic crisis of 17 events with a duration of $10 \mathrm{~min}$. on May 30, and the high rate of VT events continued for 10 days up to 35 per day with the largest magnitude 1.8 . The precursory crisis had $125 \mathrm{VT}$ events and lasted for $32 \mathrm{~min}$. The VT seismicity continued after the beginning of eruption for 8 days with magnitude up to 2.0. Within the first 11 days, the eruption tremor showed strong variations in amplitude by a factor up to 10 . From June 21 , the tremor amplitude increased significantly and stayed constant at that value. The tremor amplitude reached the highest level on July 7, and simultaneously the seismicity of VT events was intensified with magnitude up to 2.8 . The tiltmeter and extensometer records indicated deflation of the summit during this period. The eruption ended on July 7 , with the tremor amplitude increasing first and then decreasing to less than 5\% of its highest level and disappearing completely within a few hours. A swarm of LP events followed the sudden ending of eruption.

Two months after the end of eruption \#47, the seismicity of shallow VT events beneath the summit started a gradual increase in 3 months up to 50 events per day in November. Two seismic crises occurred on November 5 and 29 without eruption. The precursory crisis of the eruption \#48 started on 2002/1/5 with 370 VT events lasting for 6 hour $21 \mathrm{~min}$. It included LP events whose source migrated toward the eruption site in the NE rift zone. The eruption started from four vents located at elevations around $1900 \mathrm{~m}$. A new vent opened on January 12, $3 \mathrm{~km}$ east from the first ones with a large lava flow that reached the ocean on January 14, 2002. The eruption ended on January 16 with the lava output of 12.5 M cubic meters. There was a swarm of shallow VT events beneath the summit near the end of the eruption.

As mentioned in A9.1 a large $1 \mathrm{~Hz}$ LP event occurred following \#45 with the characteristic observed during 1980's, namely, the identical arrival times and wave forms at the three summit stations (BOR, SFR and DSR) attributed by Aki and Ferrazzini (2000) to a laterally extended magma body beneath the summit generating these events. The last time we observed an LP event with this characteristic was on October 11, 1992. For example the LP events associated with the 1998 eruption were originated from a more localized source on the north side of the central cone, and showed different waveforms and arrival times at the three stations.

The LP events observed during the period III-2A occurred always as swarms close to the ends of eruptions.

\section{A11.2 Active period of phase 2 of cycle III (III-2A): Modeling}

The above occurrence of LP events directly related to individual eruptions is very similar to that observed during the active period II-1A as described in A5.1. The first swarm in that period occurred during the precursory crisis of the eruption \#20 in the NE rift zone. The second one occurred during a complex episode of eruptions from three different vents in the summit area. The third LP swarm followed a short summit eruption and the forth one occurred shortly after the summit eruption \#23 which filled 95\% of the Dolomieu crater. Finally the last swarm in that period began shortly before the eruption \#24 in the SE rift-zone outside Enclos.

The above comparison suggests that the shallow magma system in this period has become similar to the one working during the period II-1A. In this system, magma can move more easily in the lateral direction, with eruptions in the Dolomieu-east and both rift-zones, and even into the rift zone outside Enclos.

Ferrazzini (personal communication) attributed the high VT seismicity near the end of eruptions \#45, 46 and 47 to a process of collapse under the Dolomieu crater. The lack of LP events in minor seismic crises without eruption in this period also suggested the magma movement along the vertical summit path. As described in A5.1, the high eruptive activity including the pit-crater collapse was observed also during the period II-1A supporting the similarity in the condition of the magma system.

The observed relation between the duration of the precursory crisis and the elevation of the eruption site for \#48 precisely agreed the empirical relation obtained by Aki and Ferrazzini (2000) for eruptions in the period with a welldeveloped shallow magma system.

\section{A11.3 Active period of phase 2 of cycle III (III-2A): Cause and effect}

The above similarities between this period and the period II-1A raised a serious concern about the possibility of an eruption outside the Enclos caldera as well as the explosive eruptions inside the Dolomieu crater associated with a pitcrater collapse. The eruption \#48 was threatening enough to issue an evacuation order to some villages along the NE rift-zone, but did not go outside the Enclos. The vigorous seismicity near the end of the eruption \#49 (which belongs to the next quiet period according to our classification in Table 1) resulted in a collapse in the floor of the Dolomieu crater, but did not generate any eruptive activity. Why the difference? The answer may be found in Table 1.

We notice in Table 1 that the magma remaining in the L-B patches were much greater during periods preceding II-1A as compared to those preceding III-2A. In other words, we had all the conditions of the magma system needed for the eruption outside the Enclos as well as the explosive pit-crater collapse, but we did not have enough magma to generate 
them. We had necessary conditions but not sufficient.

Swarms of LP events occurred after the eruption \#48, but disappeared in April, 2002. Their occurrence in 2002 had no relation with any eruption, suggesting the beginning of the segmented magma path as seen in the period II-2Q. while the LP activity before \#48 was directly related to individual eruptions similar to the active period II-1A.

On the other hand the VT seismicity became vigorous showing a similarity in the temporal behavior of the daily frequency of summit events to that before the eruption \#48, although the cumulative moment curve showed that the accumulated amount of seismic moment of the summit events is 10 times smaller than the corresponding period preceding \#48.

In retrospect, the high VT seismicity was related to the magma movement in the vertical path to the Dolomieu crater where a collapse occurs at the end of the eruption \#49, while the horizontal path to the rift-zone was showing the signs of segmentation as indicated in the behavior of LP events.

\section{Note added on June 22, 2004}

This appendix was included in my memo to the director of the IPGP, Claude Jaupart, dated April 16, 2003. I made no modification on the text except for re-numbering of figures and tables and few minor corrections on the grammar. A copy of the memo was submitted also to the director of the Volcanological Observatory of Piton de la Fournaise, Thomas Staudacher.

\section{References}

Aki, K., Analysis of the seismic coda of local earthquakes as scattered waves, J. Geophys. Res., 74, 615-631, 1969.

Aki, K., Scattering of P waves under the Montana LASA, J. Geophys. Res., 78, 1334-1346, 1973.

Aki, K., Interrelation between fault zone structures and earthquake processes, Pure Appl. Geophys., 145, 647-676, 1995.

Aki, K., Scale dependence in earthquake phenomena and its relevance to earthquake prediction, Proc. Nat. Acad. Sci. USA, 93, 3740-3747, 1996.

Aki, K. and V. Ferrazzini, Seismic monitoring and modeling of an active volcano for prediction, J. Geophys. Res., 105, 16617-16640, 2000.

Aki, K. and V. Ferrazzini, Comparison of Mount Etna, Kilauea and Piton de la Fournaise by a quantitative modeling of their eruption histories, $J$. Geophys. Res., 105, 16617-16640, 2001.

Aki, K. and R. Koyanagi, Deep volcanic tremor and magma ascent mechanism under Kilauea, Hawaii, J. Geophys. Res., 86, 7095-7109, 1981.

Aki, K. and P. G. Richards, Quantitative Seismology, W. H. Freeman and Company, San Francisco, 932 pp., Second edition, 2002, University Science Books, Sausalito, California, 699 pp, 1980.

Aki, K., A. Christoffersson, and E. Husebye, Determination of the threedimensional seismic structure of the lithosphere, J. Geophys. Res., 82, 277-296, 1977.

Archuleta, R., J. E. Cranswick, C. Mueller, and P. Spudich, Source parameters of the 1980 Mammoth Lakes, California, earthquake sequence, $J$. Geophys. Res., 87, 4595-4608, 1982.

Bachélery, P., Le fonctionnement des Volcans-Boucliers, Memoire, Faculte des Sciences et Technologies, Universite de la Reunion, Saint-Denis, La Reunion, France, 1999.

Battaglia, J., personal communication, 2000.

Benard, R. and M. Krafft, Au Coeur de la Fournaise, 220 pp., NouraultBenard, Saint-Denis, La Reunion, France, 1986.

Byerlee, J. D., Friction of rocks, Pure Appl. Geophys., 116, 615-626, 1978.

Cabusson, S., personal communication., 2002.

Chouet, B., Temporal variation in the attenuation of earthquake coda near Stone Canyon, California, Geophys. Res. Lett., 6, 143-146, 1979.

Ellsworth, W. L. and R. Y. Koyanagi, Three-dimensional crust and mantle structure of Kilauea volcano, Hawaii, J. Geophys. Res., 82, 5379-5394, 1977.

Hashimoto, M., Static stress changes associated with the Kobe earthquake: Calculation of changes in Coulomb failure function and comparison with sesimicity change, J. Seis. Soc. Japan, 48, 521-530, 1996.

Hiramatsu, Y., N. Hayashi, M. Furumoto, and H. Katao, Temporal change in coda $Q^{-1}$ and $b$ value due to the static stress change associated with the 1995 Hyogo-ken Nanbu earthquake, J. Geophys. Res., 105, 6141-6151, 2000.

Iio, Y., T. Sagiya, Y. Kobayashi, and I. Shiozaki, Water-weakened lower crust and its role in the concentrated deformation in the Japanese Islands, Earth Planet. Sci. Lett., 203, 245-253, 2002.

Ishibashi, K., Seismotectonic modeling of the repeating $M$ 7-class disastrous Odawara earthquake in the Izu collision zone, central Japan, Earth Planets Space, 56, this issue, 843-857, 2004.

Ito, K., Regional variations of the cutoff depth of seismicity in the crust and their relation to heat flow and large inland-earthquakes, J. Phys. Earth, 38, 223-250, 1990.

Jin, A. and K. Aki, Spatial and temporal correlation between coda $Q^{-1}$ and seismicity and its physical mechanism, J. Geophys. Res., 94, 1404114059, 1989.

Jin, A. and K. Aki, Temporal correlation between coda $Q^{-1}$ and seismicity-evidence for a structural unit in the brittle-ductile transition zone, J. Geodynamics, 17, 95-120, 1993.

Jin, A., K. Mayeda, D. Adams, and K. Aki, Separation of intrinsic and scattering attenuation in southern California using TERRAscope data, $J$. Geophys. Res., 99, 17835-17848, 1994.

Jin, A., K. Aki, Z. Liu, and V. I. Keilis-Borok, Seismological evidence for the brittle-ductile interaction hypothesis for earthquake loading, Earth Planets Space, 56, this issue, 823-830, 2004.

Katao, H., N. Maeda, Y. Hiramatsu, Y. Iio, and S. Nakao, Detailed mapping of focal mechanisms in/around the 1995 Hyogo-ken Nanbu earthquake rupture zone, J. Phys. Earth, 45, 105-119, 1997.

Keilis-Borok, V. I., Fundamentals of earthquake prediction: Four paradims, in Nonlinear Dynamics of the Lithosphere and Earthquake Prediction, edited by V. I. Keilis-Borok and A. A. Soloviev, Springer-Verlag Berlin Heidelberg New York, pp. 1-36, 2003.

Lénat, J. F. and P. Bachélery, Structure et fonctionnement de la zone centrale du Piton de la Fournaise, in Le Volcanisme de La Réunion. -Monographie-, edited by J. F. Lénat, Centre de Recherches Volcanologiques, Observatoire de Physique du Globe de Clermont-Universté Blaise Pascal and C. N. R. S., pp. 257-296, 1990.

Lénat, J. F., P. Bachélery, A. Bonneville, and A. Hirn, The beginning of the 1985-1987 eruption cycle at Piton de la Fournaise (La Reunion); New insights in the magmatic and volcano-tectonic systems, J. Volcanol. Geotherm. Res., 36, 209-232, 1989.

Obara, K., Nonvolcanic deep tremor associated with subduction in Southwest Japan, Science, 296, 1,679-1,681, 2002.

Ohnaka, M., M. Akatsu, H. Mochizuki, A. Odera, F. Tagashira, and Y. Yamamoto, A constitutive law for the shear failure of rock under lithospheric conditions, Tectonophysics, 277, 1-27, 1997.

Ohtani, T., N. Shigematsu, K. Fujimoto, Y. Miyashita, T. Tomita, H. Tanaka, and K. Omura, Hatagawa fault zone: Exhumed brittle-plastic transition zone, Proceedings of International Symposium on Slip and Flow Processes in and below the Seismogenic Region, Sendai, Japan, November 5-8, 2001, 131-135, 2001.

Okubo, Y., H. Tsu, and K. Ogawa, Estimation of Curie point temperature and geothermal structure of island arcs of Japan, Tectonophysics, 159, 279-290, 1989.

Olshansky, R. B. and R. J. Geller, Earthquake Prediction and Public Policy, in Earthquake Science and Seismic Risk Reduction, edited by F. Mulargia and R. J. Geller, Kluwer Academic Publishers, Dordrecht/Boston/London, pp. 284-329, 2003.

Sabine, W. C., Collected Papers on Acoustics, Harvard University Press, Cambridge, Mass, 1922.

Sacks, I. S. and P. A. Rydelek, Earthquake "Quanta" as an explanation for observed magnitudes and stress drops, Bull. Seism. Soc. Am., 85, 808$813,1995$.

Sato, H. and M. Fehler, Seismic Wave Propagation and Scattering in the Heterogeneous Earth, Springer-Verlag, New York, 308 pp, 1998.

Shibazaki, B., Nucleation of large earthquakes determined by the seismicaseismic boundary: Agreement between models and observations, Phys. Earth Planet. Int., 134, 129-138, 2002.

Shimazaki, Small and large earthquakes: The effects of the thickness of seismogenic layer and the free surface, in Earthquake Source Mechanics, AGU monograph 37, pp. 209-216, American Geophysical Union, 1986.

Sibson, R. H., Fault zone models, heat flow and depth distribution of earthquakes in the continental crust of the United States, Bull. Seis. Soc. Am., 72, 151-163, 1982. 
Sigmundsson, F., P. Durand, and D. Massonnet, Opening of an eruptive fissure and seaward displacement at Piton de la Fournaise volcano measured by RADARSAT on satellite rader interferometry, Geophys. Res. Lett., 26, 533-536, 1999.

Stieltjes, L. and P. Moutou, A statistical and probabilistic study of the historic activity of Piton de la Fournaise, reunion Island, Indian Ocean, $J$. Volcanol. Geotherm. Res., 36, 67-86, 1989.

Tsukuda, T., Coda Q before and after the 1983 Misasa earthquake of M6.2, Tottori Pref. Japan, PAGEOPH, 128, 261-280, 1988.

Wyss, M., Evaluation of Proposed Earthquake Precursors, Geophys. Monogr. Am. Geophys. Union, pp. 94, Washington, D.C, 1991

Yomogida, K. and R. Benites, Relation between direct wave Q and coda Q: A numerical approach, Geophys. J. Int., 123, 471-483, 1995.

Zlotnicki, J., J. C. Ruegg, P. Bachelery, and P. A. Blum, Eruptive mechanism on Piton de la Fournaise volcano associated with the December
4, and January 18, 1984 eruptions from ground deformation monitoring and photogrammetric surveys, J. Volcanol. Geotherm. Res., 40, 197-217, 1990.

Zoback, M. D. and J. Townend, Implications of hydrostatic pore pressures and high crustal strength for the deformation of intraplate lithosphere, Tectonophysics, 336, 19-30, 2001.

Zoback, M. D. and M. L. Zoback, State of stress in the Earth's lithosphere, in International Handbook of Earthquake and Engineering Seismology, Academic Press, Amsterdam, 559-568, 2002.

K. Aki (e-mail: aki@ipgp.jussieu.fr) 